\title{
On the use of computed tomography in cardiac imaging
}

\author{
Jakob De Geer
}

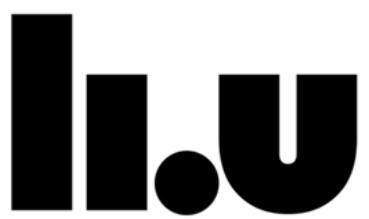

LINKÖPING UNIVERSITY

Center for Medical Image Science and Visualization (CMIV)

Division of Radiological Sciences

Department of Medical and Health Sciences

Faculty of Medicine and Health Sciences

Linköping University

SE 58183 Linköping, Sweden 
(C) Jakob De Geer, 2016

Previously published material has been reprinted with permission from the copyright holder.

All illustrations are made by the author.

Printed in Sweden by LiU-Tryck, Linköping, Sweden, 2016

ISBN: 978-91-7685-795-3

ISSN: 0345-0082 
"...even if it could be made to work as you suggest, we cannot imagine a significant market for such an expensive apparatus which would do nothing but make a radiographic cross-section of a head."

Anonymous X-ray equipment manufacturer in rejection letter to CT pioneer W.H. Oldendorf, in 1963 (1). 


\section{SUPERVISOR}

Anders Persson, Professor

CMIV and Department of Medical and Health Sciences/Radiological Sciences

Faculty of Medicine and Health Sciences, Linköping University

\section{ASSISTANT SUPERVISORS}

Jan Engvall, Professor

CMIV and Department of Medical and Health Sciences/Cardiovascular Medicine

Faculty of Medicine and Health Sciences, Linköping University

Michael Sandborg, Professor

CMIV and Department of Medical and Health Sciences/ Radiation Physics

Faculty of Medicine and Health Sciences, Linköping University

Örjan Smedby, Professor

School of Technology and Health,

KTH Royal Institute of Technology

\section{OPPONENT}

Ase Johnsson, Docent

Institute of Clinical sciences, Department of Radiology

Sahlgrenska Academy, University of Gothenburg

\section{FACULTY BOARD}

\section{Tomas Bjerner, Docent}

Department of Surgical Sciences, Radiology

Uppsala University

\section{Peter Lindholm, Docent}

Department of Physiology and Pharmacology

Karolinska Institutet

Ebo de Muinck, Professor

CMIV and Department of Medical and Health Sciences / Cardiovascular Medicine, Faculty of Medicine and Health Sciences, Linköping University 


\section{ABSTRACT}

\section{Background}

Cardiac computed tomography in general and Cardiac Computed Tomography Angiography (CCTA) in particular, is becoming increasingly useful in the work-up of coronary artery disease (CAD). The main strength of CCTA is the high negative predictive value and thus the ability to exclude significant stenosis. When more extensive atheromatous change is seen, there is a tendency of overestimation of stenosis significance, leading to a number of unnecessary invasive procedures. Several potential methods for increasing the diagnostic yield of cardiac CT are available.

\section{Purpose}

Study I: To investigate whether the use of a 2-D, non-linear adaptive noise reduction filter can improve image quality in CCTA.

Study II: To evaluate the variation in adenosine stress dynamic Computed Tomography Perfusion (CTP) blood flow as compared to ${ }^{99 \mathrm{~m}} \mathrm{Tc}$ Single Photon Emission Computed Tomography (SPECT). Secondly, to compare the perfusion results from manual and automatic myocardial segmentation.

Study III: To evaluate the accuracy of noninvasively computed fractional flow reserve (cFFR) derived from CCTA.

Study IV: To evaluate the prognostic value of CCTA in terms of major adverse cardiac events (MACE).

\section{Materials and methods}

Study I: Images from 36 consecutive CCTA exams performed with two different dose levels were used. Low-dose ( $20 \%$ of full dose) images were duplicated and one copy subjected to an external noise reduction filter. Image quality in full dose, lowdose and noise-reduced low-dose images were graded using visual grading analysis. Image noise was measured.

Study II: Stress CTP and stress SPECT were performed in 17 patients, and the variation in per segment blood flow was evaluated and compared. Also, both 
manual and automated CTP image segmentation was performed and the results compared.

Study III: A total of 21 patients with CCTA and subsequent invasive coronary angiography (ICA) including measurement of FFR were selected. The CCTA datasets were processed using cFFR software and the results compared to the corresponding invasively measured FFR (invFFR).

Study IV: A cohort of 1205 patients with chest pain of unknown origin but without known CAD underwent CCTA. CCTA findings were classified as: 1) normal, 2) non-obstructive CAD or 3) obstructive CAD. Baseline data and data on subsequent MACE were retrieved from the SWEDEHEART/SCAAR medical quality registries and from the National Board of Health Patient and Cause-ofdeath registries. Survival, hazard ratios and three-year incidence in terms of MACE were calculated for each group. The three-year incidence for readmission due to stable angina pectoris or unspecific chest pain was also calculated.

\section{Results}

Study I: There was a significant improvement in perceived image quality for all quality criteria when the filter was applied to low-dose images. The image noise for the whole group, expressed as the average standard deviation of the mean $\mathrm{HU}$ value, decreased from 70.5-59.5 $(\mathrm{p}<0.001)$ and from 67.2-55.8 $(\mathrm{p}<0.001)$ in the ascending and descending aorta respectively.

Study II: The analysis of variation (ANOVA) correlation coefficients for CTP vs. SPECT were 0.38 and $0.41(\mathrm{p}<0.001)$, for manual and automated segmentation respectively. Mean per patient CTP blood flow in normal segments varied between 94-183 $\mathrm{ml} / 100 \mathrm{ml}$ tissue/min for manual segmentation, and 104-196 ml/100 ml tissue/min for automated segmentation. The Spearman rank correlation coefficient for manual vs. automated segmentation CTP was $\rho=0.88(p<0.001)$ and the Intraclass Correlation Coefficient (ICC) was 0.93 ( $\mathrm{p}<0.001$ ).

Study III: The Spearman rank correlation coefficient for cFFR vs. invFFR was $\rho=0.77(\mathrm{p}<0.001)$ and the ICC was $0.73(\mathrm{p}<0.001)$. Sensitivity, specificity, positive predictive value and negative predictive value for significant stenosis $(\mathrm{FFR}<0.80$, per vessel) were $0.83,0.76,0.56$ and 0.93 respectively.

Study IV: The hazard ratio for non-obstructive CAD vs. normal coronary arteries was 5.13 (95\% C.I 1.03-25.43, p<0.05), and 151.40 (95\% C.I 37.03-619.08, $\mathrm{p}<0.001)$ for obstructive CAD vs. normal coronary arteries. The three-year incidence of MACE was 1.1\% for patients with normal coronary arteries on CCTA, 
$2.5 \%$ for patients with non-obstructive CAD and $42.7 \%$ for patients with obstructive CAD $(\mathrm{p}<0.001)$.

The three-year incidence of readmission for stable angina or chest pain after CCTA was $8.6 \%, 15.4 \%$ and $46.3 \%$ for normal coronary arteries, non-obstructive CAD and obstructive CAD respectively.

\section{Conclusions}

Study I: The perceived image quality and image noise in low dose images were significantly improved with the application of a 2-D, non-linear adaptive noise reduction filter, even though the improvement was small compared to the image quality of the corresponding full-dose images.

Study II: Correlation between dynamic CTP and SPECT was positive but weak. There were large variations in CTP blood flow in normal segments on SPECT, rendering the definition of an absolute cut-off value for normal vs. ischemic myocardium difficult. Manual and automatic segmentation were equally useful.

Study III: The correlation between cFFR and invFFR was good, indicating that noninvasively estimated cFFR performs on a similar level as invasively measured FFR.

Study IV: The long-term risk for MACE was very low in patients with nonobstructive CAD on CCTA, even though there seemed to be a substantial increase in the risk for MACE in patients with non-obstructive CAD as compared to normal coronary arteries. In addition, even patients with normal coronary arteries or non-obstructive CAD continued to have a substantial number of readmissions for chest pain or angina pectoris. 


\section{LIST OF PAPERS}

This thesis is based on the following original papers, referred to in the text by their Roman numerals:

I Jakob De Geer, Michael Sandborg, Örjan Smedby, Anders Persson:

The efficacy of 2-D, non-linear adaptive noise reduction filtering in cardiac imaging: a pilot study

Acta Radiol 2011; 52: 716-722.

(C) 2011 Sage Publishing. Reprinted with permission.

II Jakob De Geer, Marcus Gjerde, Lars Brudin, Eva Olsson, Anders Persson, Jan Engvall:

Large variation in blood flow between left ventricular segments, as detected by Adenosine stress dynamic CT perfusion

Clin Physiol Funct Imaging 2015 Jul;35(4):291-300.

(C) 2015 John Wiley \& Sons. Reprinted with permission

III Jakob De Geer, Mårten Sandstedt, Anders Björkholm, Joakim Alfredsson Magnus Janzon, Jan Engvall, Anders Persson:

Software-based in-bouse estimation of fractional flow reserve using standard coronary CT angiography data

Acta Radiol 2015; doi:10.1177/0284185115622075

(C) 2015 Sage Publishing. Printed with permission.

IV Mårten Sandstedt, Jakob De Geer, Jan Engvall, Anders Persson, Joakim Alfredsson:

Long-term outcome of real-life patients with chest pain of unknown origin undergoing coronary computed tomography angiography (manuscript) 


\section{ABBREVIATIONS}

2-D

3-D

AEC

AHA

ALARA

ANOVA

AP

$\mathrm{BPM}$

CAD

CAT

CCTA

cFFR

cMR

CT

CTDI

CTP

$\mathrm{Cx}$

DAP

DNA

DLP

DECT

DeFACTO

DSCT

EMI

FAME

FFR

Gy

HR

$\mathrm{HU}$

ICA

ICC
Two-dimensional

Three-dimensional

Automatic Exposure Control

American Heart Association

As Low As Reasonably Achievable

ANalysis Of Variance

Angina Pectoris

Beats Per Minute

Coronary Artery Disease

Computed Axial Tomography

Coronary Computed Tomography Angiography

CT-based Fractional Flow Reserve

cardiac Magnetic Resonance tomography

Computed Tomography

Computed Tomography Dose Index

Computed Tomography Perfusion

Circumflex coronary artery

Dose Area Product

DeoxyriboNucleic Acid

Dose Length Product

Dual Energy Computed Tomography

Determination of Fractional Flow Reserve by Anatomic Computed Tomographic Angiography (study)

Dual Source Computed Tomography

Electric and Musical Industries Ltd

Fractional Flow Reserve Versus Angiography in Multivessel Evaluation (study)

Fractional Flow Reserve

Gray

Hazard Ratio

Hounsfield Unit

Invasive Coronary Angiography

Intraclass Correlation Coefficient 


$\begin{array}{ll}\text { invFFR } & \text { Invasively measured Fractional Flow Reserve } \\ \text { kV } & \text { kiloVolt } \\ \text { LAD } & \text { Left Anterior Descending coronary artery } \\ \mathrm{mA} & \text { milliAmpere } \\ \mathrm{mAs} & \text { milliAmpere x seconds } \\ \mathrm{mL} & \text { milliLitre } \\ \mathrm{mSv} & \text { milliSievert } \\ \text { MACE } & \text { Major Adverse Cardiac Event } \\ \text { MI } & \text { Myocardial Infarction } \\ \text { MPR } & \text { MultiPlanar Reconstruction (or Reformatting) } \\ \text { MRT } & \text { Magnetic Resonance Tomography } \\ \text { mSv } & \text { milliSievert } \\ \text { NXT } & \text { Analysis of Coronary Blood Flow Using CT Angiography: } \\ & \text { Next Steps (study) } \\ \text { PCI } & \text { Percutaneous Coronary Intervention } \\ \text { PET } & \text { Positron Emission Tomography } \\ \text { PLATFORM } & \text { Prospective LongitudinAl Trial of FFRct: Outcome and } \\ \text { PTP } & \text { Resource IMpacts (study) } \\ \text { QCA } & \text { Pre-Test Probability } \\ \text { RCA } & \text { Quantitative Coronary Angiography } \\ \text { ROC } & \text { Right Coronary Artery } \\ \text { ROI } & \text { Receiver Operating Characteristic } \\ \text { SCAAR } & \text { Region Of Interest } \\ \text { SCAPIS } & \text { Swedish Coronary Angiography and Angioplasty Registry } \\ \text { SCCT } & \text { The Swedish CArdioPulmonary BioImage Study } \\ \text { SPECT } & \text { Society of Cardiovascular Computed Tomography } \\ \text { STEMI } & \text { Single-Photon Emission Tomography } \\ \text { Sv } & \text { ST-Elevation Myocardial Infarction } \\ \text { SWEDEHEART } & \text { Sievert } \\ & \text { Swedish Web-based system for Enhancement and } \\ \text { TAG } & \text { Development of Evidence-based care in Heart disease } \\ \text { VGA } & \text { Evaluated According to Recommended Therapies (registry) } \\ & \text { Transluminal Attenuation Gradient } \\ \text { Visual Grading Analysis } \\ \end{array}$




\section{CONTENTS}

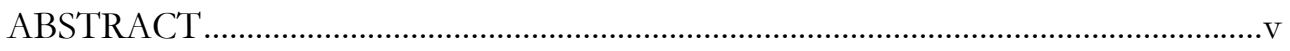

Background..............................................................................................

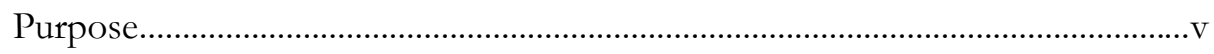

Materials and methods .................................................................................

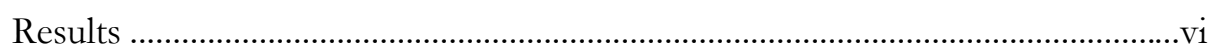

Conclusions ………………………….......................................................... vii

LIST OF PAPERS …………………………………..........................................

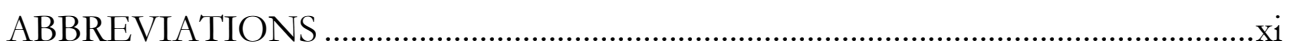

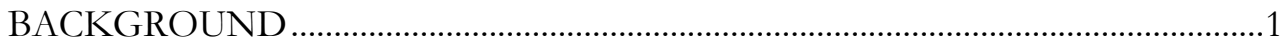

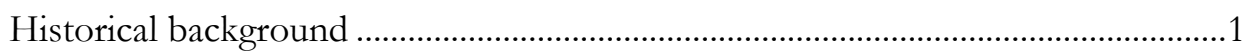

Methods for visualising coronary arteries..................................................................

Invasive Coronary Angiography (ICA) .............................................................2

Cardiac Computed Tomography Angiography (CCTA) ........................................

Functional methods for evaluating coronary artery disease ......................................

Fractional Flow Reserve (FFR) ...........................................................................

CCTA-based FFR estimation (cFFR) ............................................................6

Single Photon-Emission Computed Tomography (SPECT) …………………......

Perfusion imaging CT (CTP) .......................................................................

Perfusion imaging MR ....................................................................................

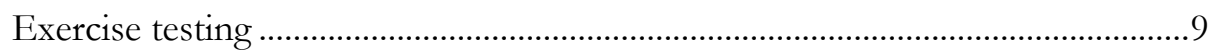

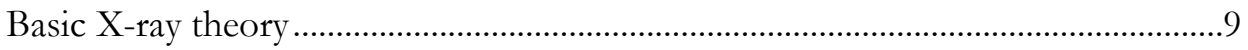

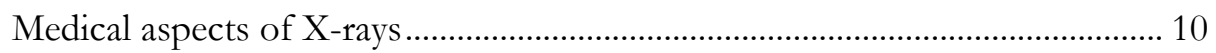

Dose estimation on CT and conventional X-ray ……....................................... 10

Image quality and strategies for reducing dose in CT........................................ 11

Methods for evaluating image quality.................................................................. 13 


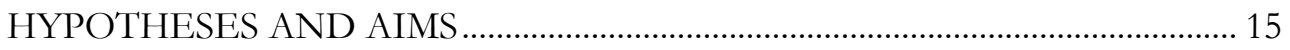

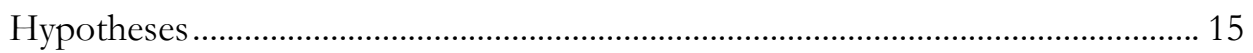

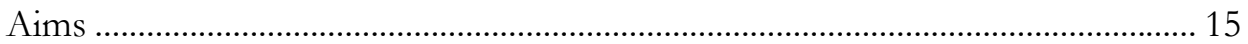

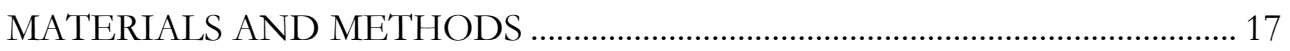

Ethical aspects ..................................................................................................... 17

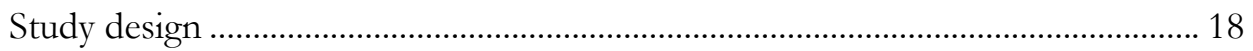

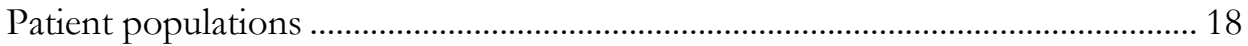

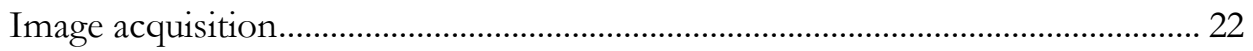

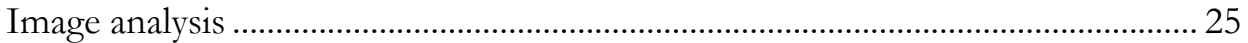

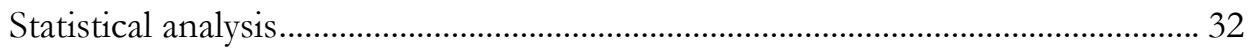

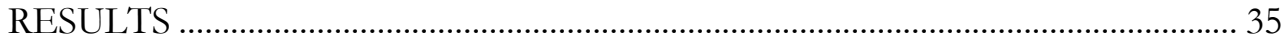

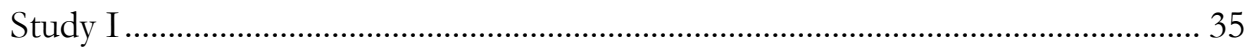

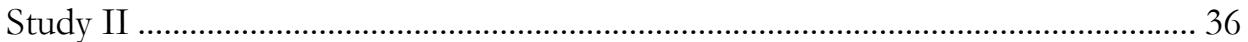

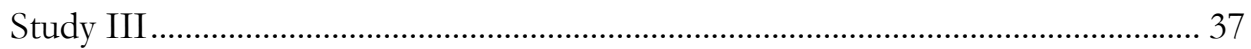

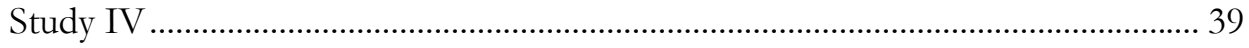

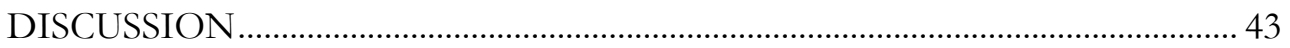

Aspects on patient selection ................................................................................. 43

Aspects on image acquisition and evaluation .......................................................... 45

Aspects on the results........................................................................................... 47

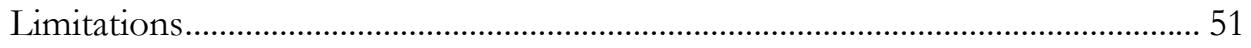

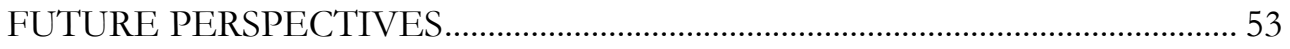

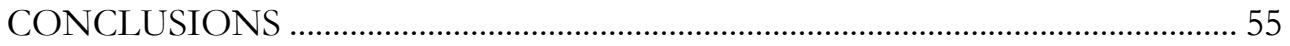

POPULÄRVETENSKAPLIG SAMMANFATTNING PÅ SVENSKA................ 57

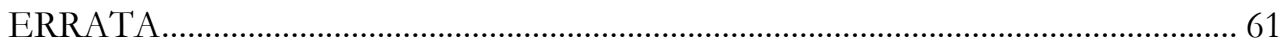

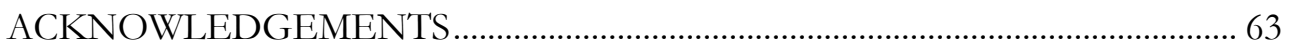

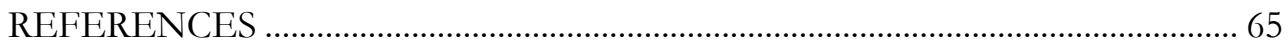

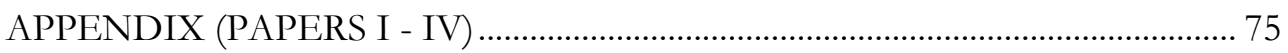






\section{BACKGROUND}

\section{Historical background}

X-ray tomography, the word itself derived from the Greek word "tomos" (slice or plane), refers to the sectional imaging of a plane, as opposed to conventional x-ray imaging where all structures between the $\mathrm{x}$-ray tube and the detector are superimposed upon each other. The concept of x-ray tomography is almost as old as the discovery of $\mathrm{x}$-rays itself, with the basic principles being developed during the 1910s and early 1920s. The first patent was registered in 1921 by the French physician André-Edmund-Marie Bocard but it was not until the 1930s that the technique came into more widespread clinical use, most notably in the hands of Italian radiologist Alessandro Vallebona (2). The technique was further developed during the following decades, eventually paving the way for the development of computed axial tomography (CT or CAT). The concept of CT was developed during the 1960s by, among others, William H. Oldendorf, Alan Cormack and Godfrey Hounsfield and culminated with the introduction of the first commercial CT-scanner, the so-called "EMI-scanner" (Fig. 1), in 1971 (3).

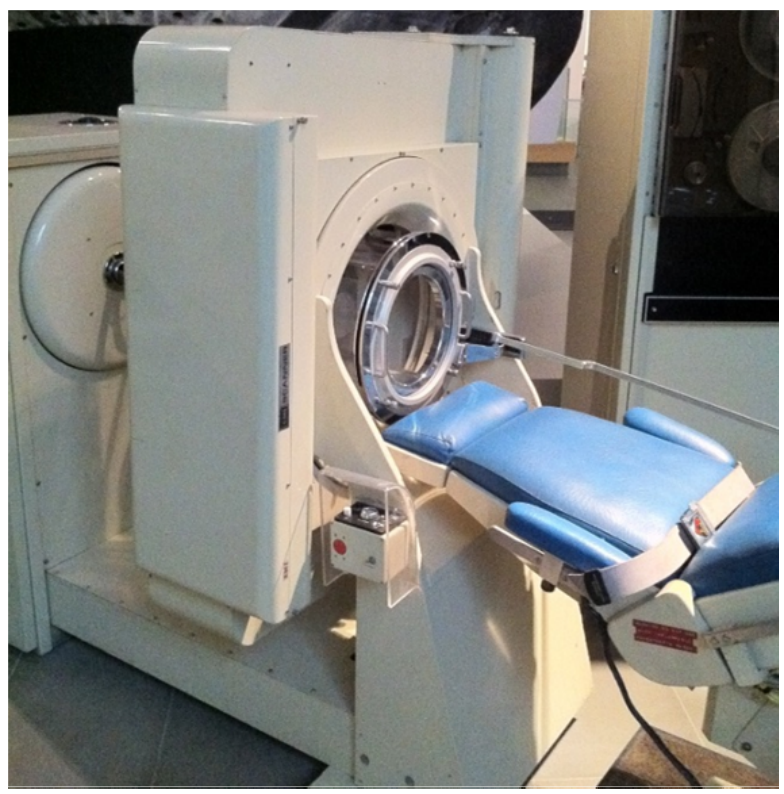

Fig. 1 EMI-scanner no.1 on display at the Science Museum, London, England. Photo by Jakob De Geer. 
The EMI-scanner was limited to scanning of the head only, but body scanning was introduced soon after by dr. Robert S. Ledley, with the so-called Automated, Computerized, Transverse Axial (ACTA) scanner in 1973 (4). These early scanners were single-step scanners and far too slow for imaging of moving organs such as the heart (although the EMI-scanner was actually designed with dual detector rows). However, the introduction of spiral CT in general (in the early 1990s), and multi-slice spiral CT in particular (late 1990s) provided the technological basis for the development of scanners that were fast enough for accurate imaging of the heart and, more importantly, the coronary arteries. The first description of coronary CT angiography (CCTA) was published in 1995 (5), although in the beginning only the proximal parts of the coronary arteries were possible to visualise as both temporal and spatial resolution were still too low.

Since then, CT technology has evolved rapidly, but even with modern scanners it has been necessary to compensate for the lack of temporal resolution by decreasing the heart rate through the use of beta-blockers. However, today's fastest scanners have a temporal resolution of 66 milliseconds which in many cases makes it possible to visualise the coronary arteries without the use of beta blockers.

\section{Methods for visualising coronary arteries}

\section{Invasive Coronary Angiography (ICA)}

Invasive coronary angiography (ICA) has for a long time been the method of choice for visualising the lumen of the coronary arteries, in order to assess the need for surgical or intravascular intervention. A small catheter is introduced via the femoral or radial artery and placed in the ostium of the relevant coronary artery. An iodine-containing contrast agent is injected in order to visualise the coronary arteries and evaluate the presence or absence of significant stenosis. Conventional ICA only depicts the lumen of the coronary artery in two dimensions at a time, although different projections are used, and sometimes simultaneously acquired using biplane systems. There is little information about intra-mural atherosclerotic plaques or their composition, and there is also no detailed information about the surrounding tissues. If a significant stenosis is found, there is usually an option to perform percutaneous coronary intervention (PCI), where a catheter is introduced into the coronary artery and a small balloon is used to dilate the vessel. In most cases, a stent is inserted into the stenotic area after dilatation, to ensure that the artery remains patent. 
However, research has shown that visual assessment of coronary artery stenoses of intermediate severity during ICA may not always be accurate and the concordance between different interventionists may also be poor (6,7). More recent data from the FAME study also showed that the functional severity of a stenosis was difficult to judge from angiographic images alone (8).

An additional technique for the evaluation of coronary stenoses is the use of Quantitative Coronary Angiography (QCA), where a quantitative component is added to the visual evaluation of a stenosis. However, like conventional coronary angiography, QCA is still limited by the 2-D-representation of a 3-D structure (9).

ICA is an invasive technique and apart from the use of contrast agent, it also carries a small but not negligible risk of adverse effects such as arterial wall dissection and arrhythmias $(10,11)$. The reported average radiation dose is 7 milliSievert ( $\mathrm{mSv}$ ) for diagnostic ICA, but average doses of up to $15.8 \mathrm{mSv}$ have been reported (12).

\section{Cardiac Computed Tomography Angiography (CCTA)}

The heart is one of the most difficult organs to visualise with CT because of its constant movement. This is especially true for the systolic phase when the ventricles with a rapid movement eject the blood into the receiving blood vessels. The heart moves the least during the middle and end of the diastolic phase and previous studies have shown that optimal overall image quality is obtained at approximately $60-65 \%$ of the R-R-interval (13), when heart motion is at its minimum (14). Also, contrary to most body tissues, perfusion of the myocardium takes place primarily during the diastolic phase, at which time the flow in the coronary arteries is at its maximum (15). Thus, CT imaging of the heart and the coronary arteries is best performed during diastole, but the short time available makes rapid image acquisition essential in order to obtain acceptable image quality. Image acquisition is usually ECG-modulated, with either prospective or retrospective gating. Prospective gating utilises sequential radiation with image acquisition during a pre-determined phase only. This facilitates a low radiation dose but the method also becomes more sensitive to irregular cardiac rhythm. Retrospective ECG-gating utilises continuous radiation, usually with ECGmodulated dose levels during different phases of the cardiac cycle, and is thus a more robust method. Apart from the coronary arteries, the use of continuous radiation also facilitates the evaluation of ventricular and valvular movement throughout the cardiac cycle, although it also increases the radiation dose manifold 
(16). Although native images can be used for calcium scoring (17), iodine contrast agent is required for the visualisation of the coronary arteries.

During the last decade, CCTA has become a viable alternative to conventional angiography for diagnostic imaging of the coronary arteries (18). Current guidelines recommend that CCTA is to be used primarily in cases with low-to intermediate pre-test probability (PTP) of coronary artery disease (CAD). When performed with the appropriate indication, it is a clinically useful tool with high sensitivity and high negative predictive value $(19,20)$. However, CCTA is currently not recommended in cases with a high PTP, as this patient category may have more to gain from conventional ICA (21-23). Despite several studies, the long-term prognostic value is not entirely clear, although a normal result on CCTA seems to indicate a good prognosis (24-28).

Compared to conventional angiography, CСТA has a number of advantages such as its non-invasive nature and the possibility to extract additional anatomical and physiological information from the image material. Also, the use of multiplanar reconstruction (MPR) enables image evaluation in three dimensions. More recent advances include the possibility to perform dynamic perfusion scans (CTP) as well as estimating the fractional flow reserve (FFR), i.e. the flow/pressure drop over a stenosis, thereby estimating stenosis significance.

Effective patient dose has steadily decreased with the emergence of better scanners and in optimal conditions, the effective patient dose can stay well below 1 $\mathrm{mSv}$ (29-31). However, with retrospective gating the dose is generally in the range of $8-10 \mathrm{mSv}(16,32)$.

The main draw-back as compared to conventional angiography is the inherent inability to perform intervention. Hitherto, there has also been a tendency for stenosis overestimation as compared to conventional coronary angiography $(18,33)$.

\section{Functional methods for evaluating coronary artery disease}

\section{Fractional Flow Reserve (FFR)}

Apart from the methods described above, additional information on stenosis significance can be obtained by measuring the pre-and post-stenotic intracoronary pressure during maximum vasodilatation, the quotient of which is referred to as the 
fractional flow reserve (FFR). In practice, the pre-stenotic pressure is measured in the aorta.

The concept of FFR was first described in 1993 (34,35) and subsequent studies have shown that a stenosis with FFR $\leq 0.75$ almost always induces ischemia, while a stenosis with FFR $0.75-0.80$ is in more of a "grey zone" area in terms of significance (36-38). Stenoses with FFR of 0.80 or more rarely induce myocardial ischemia. It has also been shown that atheromatous changes in the arterial wall can induce a significant reduction of FFR, even in the absence of a discrete stenosis (39). Thus FFR provides the interventionist with additional information on stenosis significance and a relatively clear cut-off value, thus aiding in the decision-making on whether to perform PCI.

Measuring FFR is an invasive procedure which requires an additional passage with a special pressure sensor-equipped guide wire, and also the use of additional radiation, contrast agent and intracoronary or intravenous Adenosine.

\section{Basic theory}

FFR is defined as the as the ratio of maximal myocardial blood flow in a diseased artery as compared to the flow as it would be in the same artery if it was normal $(34,36)$. Although difficult to measure in practice, it has been shown that the blood flow can be approximated by measuring the intravascular pressure, according to the formulas below (40). The basic assumption that has to be made is that the coronary resistance is constant and minimal, allowing for the resistance to be taken out of the equation, as described below :

$$
\mathrm{FFR}=\frac{\mathrm{Q}_{\mathrm{S}}^{\max }}{\mathrm{Q}_{\mathrm{N}}^{\max }}
$$

where $\mathrm{Q}_{\mathrm{S}}^{\max }$ is the maximum flow in the stenotic area, and $\mathrm{Q}_{\mathrm{N}}^{\max }$ is the maximum flow in the normal artery.

Flow (Q) can be expressed as the quotient between the pressure difference and resistance, yielding the formula:

$$
F F R=\frac{\left[\left(\mathrm{P}_{\mathrm{d}}-\mathrm{P}_{\mathrm{v}}\right) / \mathrm{R}_{\mathrm{S}}^{\max }\right]}{\left[\left(\mathrm{P}_{\mathrm{a}}-\mathrm{P}_{\mathrm{v}}\right) / \mathrm{R}_{\mathrm{N}}^{\max }\right]}
$$

where $P_{d}$ is the pressure in the coronary artery distal to the stenosis, $P_{a}$ is the pressure in the aorta and $P_{v}$ is the venous pressure. At maximum vasodilatation, the resistances are assumed to be equal, and thus cancel out: 
Background

$$
\text { FFR }=\frac{\left(P_{d}-P_{v}\right)_{S}^{\max }}{\left(P_{a}-P_{v}\right)_{N}^{\max }}
$$

Venous pressure is considered to be negligible as compared to arterial pressure.

Thus:

$$
\mathrm{FFR}=\frac{\mathrm{P}_{\mathrm{d}}}{\mathrm{P}_{\mathrm{a}}}
$$

\section{CCTA-based FFR estimation (cFFR)}

In fluid dynamics, the so-called Navier-Stokes equations are used to calculate the flow of fluids and gases $(41,42)$. The Navier-Stokes equations are derivatives of Newtons second law of motion ("The acceleration of an object as produced by a net force is directly proportional to the magnitude of the net force, in the same direction as the net force, and inversely proportional to the mass of the object".) and hence relate to the conservation of mass and momentum. Their use is widespread and applications can be found in as disparate areas as aeronautical design and, as in this case, intra-arterial blood flow. However, the Navier-Stokes equations can be solved analytically only when under ideal circumstances such as in steady flow or in an ideal vessel. In more realistic circumstances, the equations must be solved numerically (i.e. computationally), in order to approximate velocity and pressure. This is done by simultaneous, time-resolved computation of a huge number of differential equations, typically requiring equally vast computer power $(42,43)$.

The CCTA-based computation of blood flow requires that a domain of interest is defined and that boundary conditions, or mathematical relationships between the variables of interest at the boundaries of that domain, are established. The domain of interest when computing coronary artery flow is the arterial lumen and the relevant boundaries are the vessel walls, the inlet (aortic root) and the outlets (the distal end of the coronary arteries and the ascending aorta) (42-44). The hyperemic state induced by adenosine in invFFR must also be simulated. 


\section{Single Photon-Emission Computed Tomography (SPECT)}

In spite of other emerging technologies, SPECT is still the most widely used method for visualising myocardial perfusion. SPECT is a nuclear medicine method combining a gamma camera with tomographic imaging, allowing for a 3-D presentation of the results. It is performed by injecting a radionuclide labeled carrier molecule into the bloodstream, which is subsequently deposited in the target organ. The gamma rays emitted by the radionuclide are detected, with imaging taking place approximately 30-60 minutes after radionuclide administration $(45,46)$. The most common radionuclide used for myocardial perfusion imaging today is ${ }^{99 \mathrm{~m}}$ Technetium ( ${ }^{99 \mathrm{~m}} \mathrm{Tc}$ ), although older radionuclides such as Thallium $\left({ }^{201} \mathrm{Tl}\right) \mathrm{may}$ also be used. Commonly used carrier molecules are ${ }^{99 \mathrm{~m} T \mathrm{Tc}-2-}$ methoxyisobutylisonitrile (Sestamibi/Cardiolite $\left(\right.$ ) $\quad$ or $\quad{ }^{99} \mathrm{~m}$ Tc-1,2-bis[bis(2ethoxyethyl) phosphino]ethane (Tetrofosmin/Myoview $\left.{ }^{\circledR}\right)$. These substances are transported over the cell membrane and deposited in the mitochondria $(47,48)$. The relationship between myocardial blood flow and tracer uptake has been shown to be fairly linear within the range of normal resting coronary flow, although with a flat gradient which makes quantitative differentiation difficult. Uptake rolls off when flow exceeds approximately $200 \mathrm{ml} / 100 \mathrm{ml}$ tissue / min. Thus, at higher flow SPECT tends to underestimate the uptake in relation to the blood flow. Conversely, at very low flow $(<20 \mathrm{ml} / 100 \mathrm{~g}$ tissue $/ \mathrm{min})$ SPECT is reported to overestimate the uptake in relation to the blood flow, possibly because of a more effective tissue extraction $(48,49)$. Also, in damaged but still viable myocardium, SPECT with tetrofosmin has been reported to overestimate perfusion deficits in relation to blood flow as measured by quantitative ${ }^{15} \mathrm{O}$-water PET, probably due to reduced viability of the ion pumps $\left(\mathrm{Na}^{+} / \mathrm{H}^{+}\right)$in the cell membrane (50).

Since a stenosis of $80-85 \%$ is required for the detection of significant perfusion deficiency at rest $(51,52)$, myocardial SPECT usually needs to be performed as a stress exam, using either pharmacological stress or exercise testing. If the stress exam is normal, no further imaging is necessary. However, if uptake deficiencies are visualised in the myocardium during stress, further imaging under resting conditions is needed in order to differentiate between CAD-induced hypoperfusion and manifest infarction. In Sweden and many other countries, it is common practice to perform myocardial SPECT as a 2-day protocol, but under certain conditions it is also possible to perform both exams in one day (45).

The evaluation of myocardial SPECT is most frequently visual, although computers are used for display of various cut planes as well as polar maps. A semiquantitative approach is also possible, with segmental perfusion being expressed as a percentage of the highest recorded uptake in that particular exam. The lack of 
quantitative data means that extensive three-vessel disease, with so-called balanced ischemia in the entire myocardium, might go unnoticed (53).

\section{Perfusion imaging CT (CTP)}

A number of different methods for evaluating myocardial perfusion using CT have been proposed (54). These include the use of so-called late enhancement, where imaging is performed after a pre-determined time delay, usually 5-15 minutes (55) after contrast injection. At this time point, most of the contrast agent has been washed out from healthy myocardium whereas the decreased vascularity in infarcted areas causes pooling of the contrast agent. Another proposed method is single shot, first-pass image acquisition during the contrast inflow phase, where hypoperfused areas will show less attenuation than the surrounding, normally perfused myocardium. With this method, timing is essential as the time window for optimal contrast between normal and ischemic myocardium only lasts for approximately 8 seconds (56).

A third method, which has become feasible with the emergence of scanners with higher temporal resolution and more advanced acquisition protocols, is dynamic CTP imaging. With dynamic CTP, myocardial perfusion is visualised through repeated imaging during the first pass contrast inflow in the myocardium. The change in myocardial attenuation during this period is detected and forms the basis for a quantitative estimation of myocardial blood flow (57-61). There are a number of critical pre-requisites for this approach: the scanning of the left ventricle must be fast to be able to detect the short-lived phase of increase in attenuation that comes with the wash-in of contrast, and the x-ray detector has to be large enough to allow coverage of the entire heart.

CT-based methods have a number of advantages when compared to MR and SPECT. The short acquisition time reduces the risk of motion artefacts, and there are no restrictions or contra-indications to the method in itself (although there may be to the use of iodinated contrast agent and Adenosine). The rapid image acquisition in combination with a short and comparatively wide gantry is useful when examining patients with claustrophobia. It is also possible to combine CT perfusion imaging with other types of exams, such as a standard CCTA scan. 


\section{Perfusion imaging MR}

In analogy with CT perfusion imaging, Cardiac MR (cMR) perfusion imaging can be performed using either a Gadolinium-enhanced first-pass imaging protocol, or a late enhancement protocol with image acquisition at approximately 10-20 minutes after Gadolinium administration. MR imaging with ECG-gating also allows for extensive evaluation of ventricular movement throughout the cardiac cycle. Apart from general MR-related restrictions regarding pacemakers and metallic implants, the main drawbacks are the long exam times which increases the risk of motion artefacts and patient claustrophobia.

\section{Exercise testing}

Although not an imaging method, the use of exercise testing is still a clinically important method when evaluating coronary artery disease. The reproducibility of symptoms during exercise in combination with other parameters, such as ECGreaction, work capacity, heart rate and blood pressure, yield important information about the presence and extent of coronary artery disease, and also about its functional impact.

\section{Basic X-ray theory}

$\mathrm{X}$-rays are a form of electromagnetic radiation, with wavelengths in the range 0,01 10 nanometers (nm) and a frequency between $3 \times 10^{16}$ and $3 \times 10^{19}$ hertz, placing them in between ultraviolet light and $\gamma$-radiation in the electromagnetic spectrum. The production of x-rays, for CT as well as conventional X-ray imaging, relies on the conversion of the kinetic energy attained by electrons being accelerated under the influence of a potential difference, to electromagnetic radiation. This process takes place in the x-ray tube where an electron cloud is built up through intense heating of a negatively charged cathode. During exposure, a high voltage ("tube voltage"), typically ranging between 50 and 150 kilovolt $(\mathrm{kV})$ for CT, is applied and the electrons are accelerated towards the positive anode. The number of electrons that travel between the cathode and the anode defines the tube current, with $6.24 \mathrm{x}$ $10^{15}$ electrons per second equaling 1 milliAmpere $(\mathrm{mA})$. The formation of $\mathrm{x}$-rays occur when the electrons to a variable degree decelerates in the vicinity of the positively charged nuclei of the anode material (usually tungsten). The kinetic energy of the electrons is converted to electromagnetic radiation through a process 
known as "brehmsstrahlung", the resulting energy for each electron being dependent on the distance to the nucleus at the point of interaction. Thus, the resulting $\mathrm{x}$-ray energies are all different and are presented as a spectrum (62).

\section{Medical aspects of $X$-rays}

$\mathrm{X}$-rays belong, alongside $\alpha$-, $\beta$ - and $\gamma$-radiation, to the ionising kind of electromagnetic radiation. This means they have the capability to alter the electron layers of an atom, thereby converting it into an ion. When this happens in a cell, the result may be alterations in the cell DNA. Usually, these damages will be repaired but in a small number of cases they might lead to more pronounced biological damage. This damage can be either deterministic, where the damage is foreseeable and proportional to the degree of exposure, or stochastic, where exposure may or may not lead to biological damage such as cancer. The risk of biological changes is the main reason for minimising patient dose in any x-raybased exam, and the basic principle of "As Low As Reasonably Achievable" (ALARA) is generally applied every time an x-ray-based exam is considered.

The generally accepted theory of the relationship between low-dose radiation $(<100 \mathrm{mSv})$ and adverse health effects is the so-called linear, no-threshold model, which states that the relationship between dose and the risk of cancer is linear and without threshold. Thus, even a very low dose is considered to be potentially harmful $(63,64)$. However this model is debated and several authors question its legitimacy $(65,66)$.

\section{Dose estimation on CT and conventional X-ray}

For the individual patient, there is no practical way of determining the exact dose deposited during a particular exam. Instead, all clinically obtained dose data are estimates, although partially based on different kinds of measurements (67).

For CT, the basic unit for estimation of dose (D) is the Computed Tomography Dose Index (CTDI, mGy). CTDI is established for every CT scanner through the use of dosimeter-equipped phantoms and is, through a series of steps, used to calculate the dose length product (DLP) (68). The total DLP (DLP $\left.P_{\text {tot }}\right)$ is the sum of the DLP of all series in one exam. The effective patient dose $(\mathrm{E})$ is then estimated by multiplying $\mathrm{DLP}_{\text {tot }}$ with a body-part specific coefficient $\mathrm{E}_{\mathrm{DLP}}$ $(\mathrm{mSv} / \mathrm{mGy} \times \mathrm{cm})$ using the formula: 


$$
\mathrm{E}=\mathrm{E}_{\mathrm{DLP}} \mathrm{x} \mathrm{DLP}_{\mathrm{tot}}(\mathrm{mSv})
$$

The value of $E_{\text {DLP }}$ has varied over time but is generally estimated to 0,014 or 0.018 for the thorax $(69,70)$, although some authors consider a significantly higher value of 0.030 to be appropriate for CCTA (71). Hence, the effective dose E is an estimate which takes into account the location and radiosensitivity of the irradiated tissue. Effective dose $(\mathrm{E})$ is measured in joules per kilogram $(\mathrm{J} / \mathrm{kg})$, and the SI unit in this particular case is named Sievert (Sv).

For conventional $x$-ray, including angiography, the stated dose is an estimate based on the so-called Dose-Area Product (DAP, Gycm²) which is the dose as measured by an ionisation chamber at the level of the $\mathrm{x}$-ray tube. This value is multiplied by an organ-specific coefficient $\left(\mathrm{E}_{\mathrm{DAP}}, \mathrm{mSv} / \mathrm{Gycm}^{2}\right)$ to yield the estimated dose deposited in that particular organ. For coronary artery angiography, $\mathrm{E}_{\mathrm{DAP}}=0,18 \mathrm{Gycm}^{2}(72)$.

\section{Image quality and strategies for reducing dose in CT}

In technical terms, CT image quality is based on four different factors: image contrast, image spatial resolution, image noise and artefacts $(73,74)$.

Image noise is due to random fluctuations around the average measured CT value (or Hounsfield Unit-value, HU), and is hence proportional to the standard deviation of this value. Its magnitude is dependent on the number of photons that contribute to the formation of the image and is thus affected by the tube current, the scan time, the slice thickness and the tube voltage. Thus, for any reduction of image noise, there is usually a trade-off in the form of increased dose.

However, the radiation dose necessary for adequate image quality has steadily decreased with the introduction of different dose reduction measures and more sophisticated detectors which generate less noise. A number of different technical solutions are presented below. Although not the focus of this thesis, patient positioning also plays a crucial role $(75,76)$.

\section{Automatic exposure control}

Automatic exposure control (AEC) is a standard feature on most modern CT scanners. AEC can be performed in an angular and/or longitudinal fashion and usually involves adjustment of the tube current in order to compensate for irregular patient size and shape, and for the variable density/attenuation of the human body. 
It has been shown that AEC can reduce the necessary dose with $20-30 \%$ while retaining sufficient image quality for diagnosis (77).

\section{Detector development}

The dose efficiency of a detector depends on the ability to capture and detect as large a proportion as possible of the primary x-rays exiting the patient. To achieve this, both the geometric efficiency of the scanner/detector and the absorption efficiency of the detector elements need to be considered. Electrical noise also needs to be addressed and kept at a minimum (73).

\section{Dual source CT (DSCT) and High-pitch protocols}

The introduction of dual source CT scanners in 2005 (78), allowed for a much higher temporal resolution (79) and paved the way for the use of high-pitch protocols which were able to cover the entire heart in just one heartbeat. Before that, a typical CCTA would yield an average effective dose of up to approximately $16 \mathrm{mSv}$ dose (12). However, with a high pitch of $>3$ it has been possible to reduce the dose to sub-mSv levels when the circumstances are optimal $(30,31)$.

\section{Iterative reconstruction}

Iterative reconstruction is based on repetitive comparisons between estimated and measured image data, which results in decreased image noise and less artefacts as compared to the more commonly used filtered back projection technique (80-82). Reconstruction can be performed on raw data, on image data, or on both, with a potential dose reduction of approximately $30-70 \%$ depending on the technique (8385). Since the process requires more computer power than filtered back projection, it has not reached clinical use until relatively recently. However, simplified algorithms in conjunction with advances in computer technology have led to a more widespread use.

\section{Noise reduction filters}

Filtering solutions include 2-dimensional and 3-dimensional adaptive noise reduction filters, which have been shown to be able to facilitate a significant dose reduction for a number of different applications. In essence, adaptive non-linear filters work by estimating the local orientation in each pixel (2-D) or voxel (3-D), and letting this determine the degree of smoothing applied in that particular pixel/voxel. 


\section{Methods for evaluating image quality}

There are several methods available for the assessment and quantification of image quality. Perhaps the most accurate form is Receiver Operating Characteristic (ROC) analysis. ROC analysis has its roots in signal detection analysis where the detection of low contrast signals against a noisy background is described (86). In the image quality context, this is translated into the measurement of the observers' ability to detect a certain lesion in the image. However, the images can only be categorised as normal or abnormal, and there are also difficulties in handling multiple lesions in the same image. Thus, the image data set has to be carefully selected accordingly.

A more convenient way is the use of visual grading analysis (VGA), which is based on the assessment of important anatomical structures, either with (relative VGA) or without (absolute VGA) a reference image. Image quality is graded depending on the extent to which a particular anatomical structure is evaluable, and assessment is often based on an established standard such as the European Guidelines for Image quality (70). The basic assumption that has to be made is that the visibility of normal anatomical structures correlates with the detectability of pathological lesions $(86,87)$. 
Background 


\section{HYPOTHESES AND AIMS}

The overall focus of this thesis has been the exploration of potential methods of improving the diagnostic yield of CCTA. These include image quality improvement and different functional applications, but also evaluation of the long-term prognostic value of CCTA. The specific hypotheses and aims for each study are presented below.

\section{Hypotheses}

I That the image quality of low-dose CCTA images can be improved by the use of a 2-dimensional, non-linear adaptive noise reduction filter.

II That adenosine stress dynamic CT perfusion blood flow values correlate to myocardial blood flow as visualised by ${ }^{99 \mathrm{~m}} \mathrm{Tc}$ SPECT. Secondly, that automated segmentation of the myocardium according to the AHA 17-segment model corresponds to manual segmentation, in terms of CTP blood flow.

III That noninvasive computed fractional flow reserve (cFFR) values correspond to invasively obtained measurements.

IV That patient prognosis in terms of major adverse cardiac events (MACE) varies depending on the presence or absence of atheromatosis as well as of obstructive CAD on CCTA.

\section{Aims}

I To investigate whether the use of a 2-D, non-linear adaptive noise reduction filter can improve image quality in cardiac computed tomography angiography.

II To evaluate the variation in adenosine stress dynamic CTP blood flow as compared to ${ }^{99 \mathrm{~m}} \mathrm{Tc}$ SPECT. Secondly, to compare per-segment CTP perfusion results from manual and automatic myocardial segmentation. 
Hypotheses and Aims

III To evaluate the degree to which noninvasive cFFR derived from CCTA agrees with invasively obtained FFR.

IV To evaluate the prognostic value of CCTA in terms of MACE, depending on the presence or absence of atheromatosis and/or obstructive CAD. 


\section{MATERIALS AND METHODS}

All studies were performed at Linköping University Hospital, using image data collected at CMIV/Department of Radiology. Additional clinical data, when required, was acquired from the Radiology Information System (RIS), the patient medical records, the SWEDEHEART/SCAAR medical quality registry (88), and from the Patient- and Cause-of-death-registries of the National Board of Health and Welfare (Socialstyrelsen).

\section{Ethical aspects}

All studies in this thesis were conducted according to the principles set forward in the declaration of Helsinki, and according to Swedish law and Good Clinical Practice. Permission was obtained from the regional ethical review board in study II-IV.

Study I was conducted as a dedicated image quality study, using anonymised single images from previously performed clinical exams. No extra radiation was added, and no further diagnostic evaluation was performed. Thus, no ethical permit was required according to the standard procedure at the time.

Study II (ethical permit Dnr M207-08) involved exposure to rather high radiation doses from both CT and SPECT. Radiation dose was kept at a minimum, but the patients were still exposed to approximately twice the amount of radiation required for clinical purposes. They also received additional iodinated contrast agent, Adenosine and radionuclides. Informed consent was obtained from the patients at inclusion, and they were free to withdraw from the study at any time.

Study III (ethical permit Dnr M6-09 with amendment 2013/278-32), utilised image data from previously performed, clinical CCTA exams. There was no additional imaging and all included patients had already been examined using the relevant gold standard. All patients were included in the SWEDEHEART registry and had thus agreed in general to their image and clinical data being used in future studies. Hence, informed consent for this study was waived. 
Study IV (Dnr M6-09 with amendments Dnr 2013/278-32 and 2015/112-32) was conducted using registry data from a large number of patients, some of which was anonymised. All patients were included in the SWEDEHEART medical quality registry and had agreed in general to their data being used for research. Thus, informed consent was waived.

\section{Study design}

Study $\mathbf{I}$ is a retrospective experimental image quality study, using image data from consecutive CCTA exams performed during a period of one month..

Study II is a prospective experimental study on specifically selected patients, evaluating the novel technology of dynamic CT perfusion imaging.

Study III is a retrospective experimental study, evaluating the performance of CCTA-based FFR estimation.

Study IV is a retrospective, large scale observational study on prospectively collected data, evaluating the prognostic value of CCTA in relation to cardiacrelated morbidity, mortality, intervention and hospital admission.

\section{Patient populations}

Patients included in study I and III-IV come from a cohort of 3038 clinical CCTA performed at CMIV and Linköping University Hospital between July 12007 and December 14 2014. Patients in study II were examined for research purposes only. Some patients may appear in two or more of the included studies, although no attempt has been made to further explore to what extent this is the case. Study I, III and IV were retrospective and used only already available image data from clinical exams. Thus, no further radiation or contrast agent was given to the patients included in these studies.

\section{Study I}

In study I, 47 consecutive CCTA exams, performed during one particular month in early 2008, were evaluated for inclusion. A total of eleven cases were excluded due 
to the image material not conforming with the study protocol, leaving 36 cases in the study (Fig. 2).

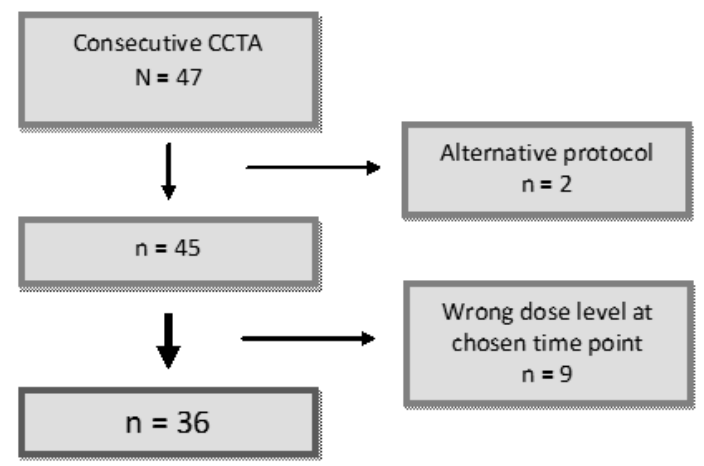

Fig. 2. Patient selection, study I

\section{Study II}

In study II, the participating patients were carefully selected from a post infarction population attending the cardiac out-patient clinic at Linköping University Hospital. The relevant exams were performed between May 2009 and March 2011.

The participants were included specifically for having a history of at least one ST-elevation myocardial infarction (STEMI) with subsequent PCI, where at least one significant stenosis had been left untreated. A total of 17 patients with these particular prerequisites were identified and examined but due to technical and methodological difficulties, only eight exams were deemed readable. The exclusion process is described in Fig. 3. 
Materials and Methods

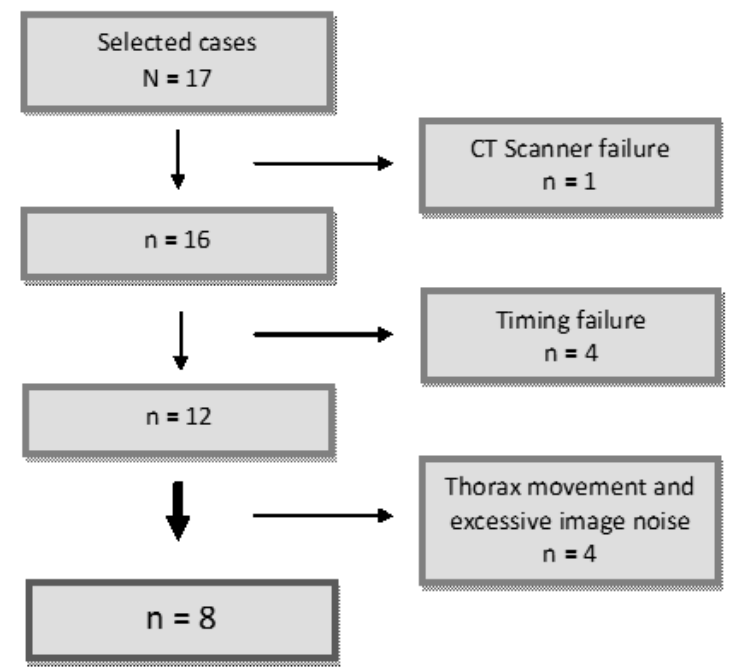

Fig. 3. Patient selection, study II

\section{Study III}

In study III all CCTA examinations performed on one particular CT scanner between September 2009 and March 2012 ( $\mathrm{n}=1396)$ were surveyed for inclusion. Eligible patients were those who had been referred to invasive angiography within 120 days of a CCTA, and where invFFR had been measured in one or more of the main epicardial arteries (except in the left main artery). In all, 63 patients with invasive FFR measurements in 71 vessels were identified. A total of 42 patients $/ 48$ vessels were excluded, the most common reason being the lack of angiographic images depicting the pressure guide wire position (21 patients/22 vessels). After further exclusions (Fig. 4), the final sample consisted of 23 FFR measurements in 21 patients. 


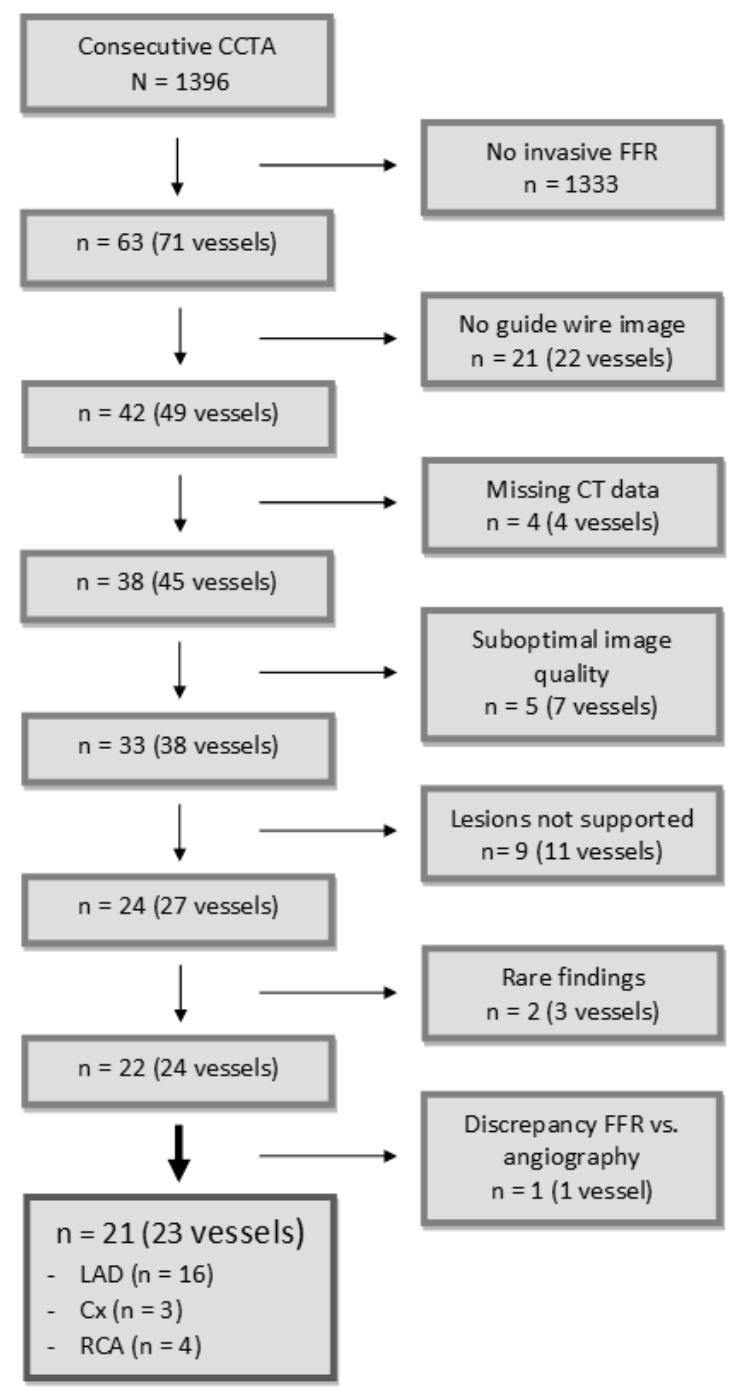

Fig. 4. Patient selection, study III.

$\mathrm{LAD}=$ Left anterior descending coronary artery. $\mathrm{Cx}=$ Circumflex coronary artery, $\mathrm{RCA}=$ Right coronary artery.

\section{Study IV}

All CCTA exams in the study performed at CMIV/Linköping University Hospital between July 12007 and December 312014 (N=3038) were evaluated for participation in the study. 
Patients with a known previous history of coronary heart disease and/or intervention were excluded, as well as all patients where CCTA was performed with other cardiac-related indications, such as valvular disease or arrhythmia $(\mathrm{n}=1668)$. All exams where image quality was deemed inadequate were also excluded $(n=144)$. Since the aim was to investigate patients with no known previous history of coronary artery disease, exams where the patient had been through a previous CCTA were also excluded, except when a second exam was performed due to inadequate image quality at the first attempt. Thus, the final study population consisted of 1205 previously not examined patients, who were all referred for examination due to chest pain of unknown origin (Fig. 5).

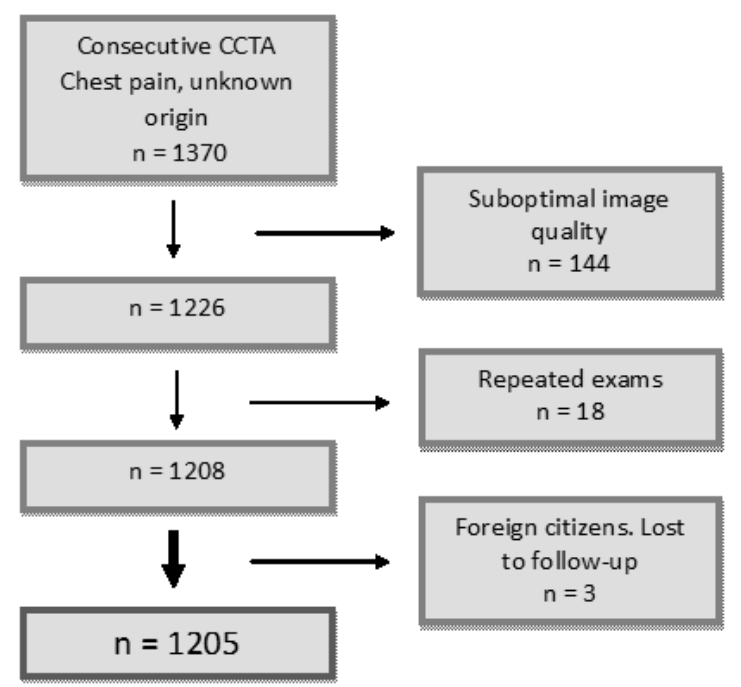

Fig. 5. Patient selection, study IV.

\section{Image acquisition}

Four different CT scanners were used throughout the study period: one 64-slice dual source CT (Somatom Definition, Siemens, Forchheim, Germany, 2007-2009) and two 128-slice dual source scanners (SOMATOM Definition FLASH and Definition FLASH with Stellar detector, Siemens, Forchheim, Germany, 2009-2012 and 2012-2014 respectively). The last few months of the study period, a 192-slice dual source scanner was used (SOMATOM Force, Siemens, Forchheim Germany). 
However, only study IV contains results from different scanners. In study II, patients also underwent a SPECT-exam and a dedicated dynamic CTP exam.

\section{Study I}

For the 64-slice dual source CT-scanner used in study I, the standard protocol included ECG-modulated tube current and retrospective ECG-gating, with different settings depending on body mass (ref. mAs 380, $100 \mathrm{kV}$, pitch 0.29 for patients $<90 \mathrm{~kg}$ and ref. $\mathrm{mAs} 310,120 \mathrm{kV}$, pitch 0.25 for patients $>90 \mathrm{~kg}$; rotation time $0.33 \mathrm{~s})$. Due to the clinical nature of the material, protocol selection was somewhat inconsistent, with the $120 \mathrm{kV}$ protocol being used in six patients weighing less than $90 \mathrm{~kg}$. Thus, a total of 24 patients were examined with a $120 \mathrm{kV}$ protocol (mean $87.8 \mathrm{~kg}$, range $65-108 \mathrm{~kg}$ ) and 12 with a $100 \mathrm{kV}$ protocol (mean $68.5 \mathrm{~kg}$, range $51-87 \mathrm{~kg})$.

\section{Study II}

Although a CCTA was performed on all patients in study II, focus was on dynamic stress CT perfusion imaging, In order to obtain reference perfusion imaging alongside CTP, a stress and rest SPECT exam was also performed. No rest CTP imaging was performed. No beta blockers or Nitroglycerin were administered.

\section{Image acquisition: CTP}

CTP images were acquired using a dual source/dual energy CT scanner (Definition Flash, Siemens, Forcheim, Germany) in mono-energetic dynamic perfusion mode (ref. mAs 300, 100kV, rotation time $0.285 \mathrm{~s}$ ).

A test bolus was used to determine the appropriate scan delay in relation to the contrast infusion (Fig. 6). The delay was initially set at 5 seconds less than the time needed for the bolus to reach the ascending aorta, but was changed to 8 seconds halfway through the study. 
Materials and Methods

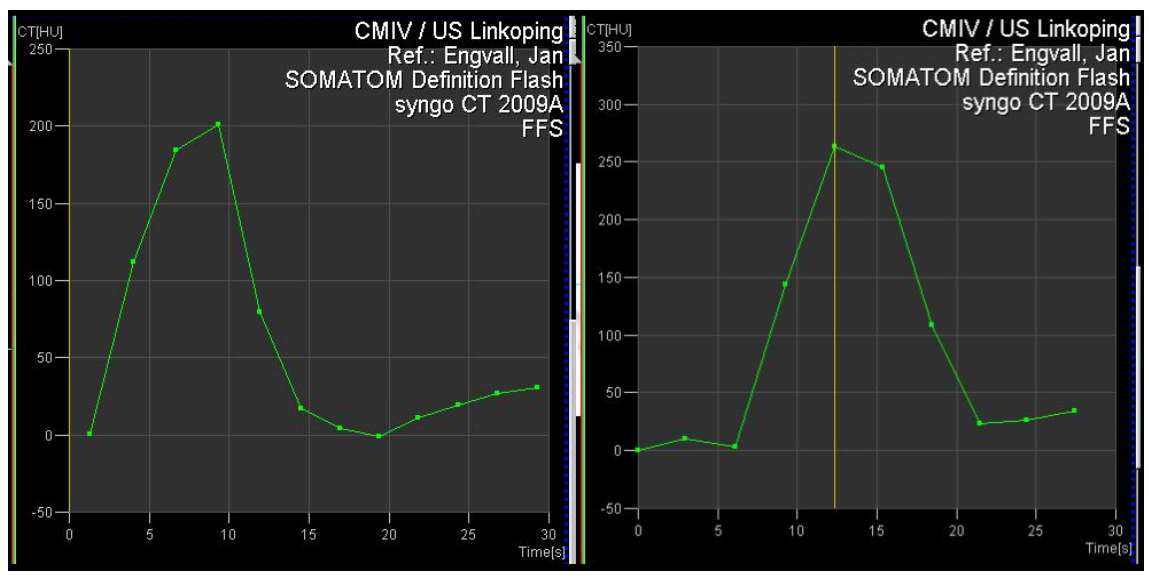

Fig. 6. Time-attenuation curves depicting the myocardial contrast inflow. Left: Imaging commences too late, and thus no baseline is visualised before contrast inflow. Right: Correct timing.

After the test bolus, a 5-minute Adenosine infusion (140 $\mu \mathrm{g} / \mathrm{kg} / \mathrm{min})$ was started, with injection of ${ }^{99 \mathrm{~m}} \mathrm{Tc}$-tetrofosmin and iodinated contrast media, and subsequent CTP imaging commencing approximately 3 minutes later (Fig. 7).

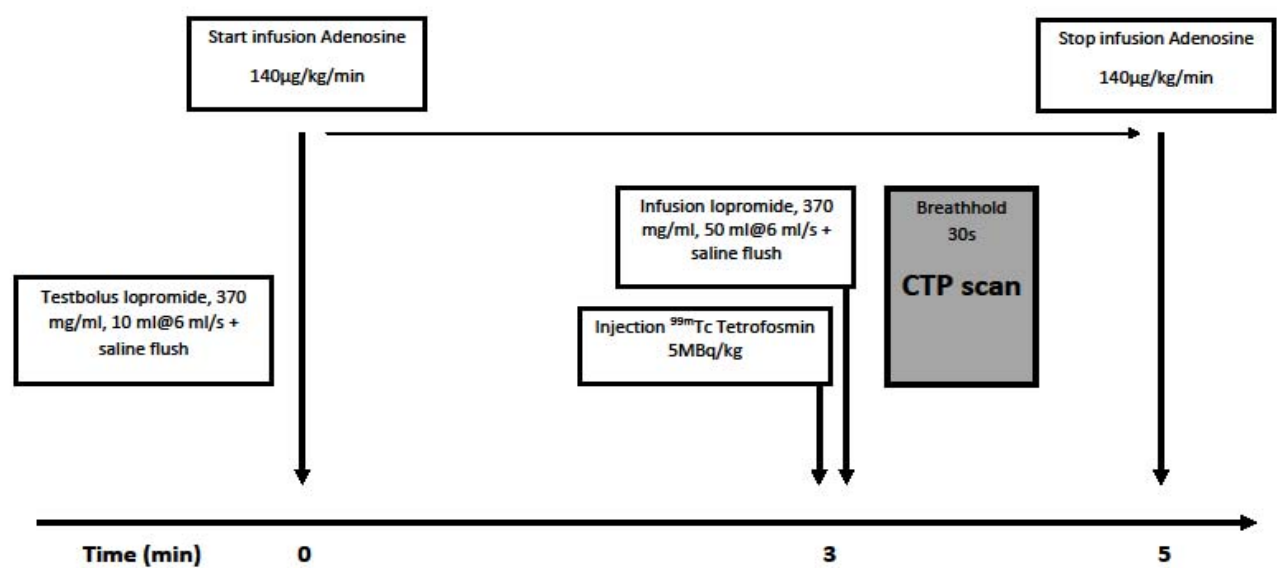

Fig. 7. Graphic description of the stress CTP image acquisition process.

CTP data was obtained through alternate imaging of two $3.8 \mathrm{~cm}$ thick, slightly overlapping axial slabs every 2 seconds for at least 30 seconds, resulting in a total coverage over the heart of $7.3 \mathrm{~cm}$. 


\section{Image acquisition: SPECT}

After completion of the CTP scan, and approximately one hour after the injection of ${ }^{99 \mathrm{~m}} \mathrm{Tc}$-tetrofosmin and Adenosine, the patients underwent a standard-of-care stress SPECT scan in a $90^{\circ}$ ("L-mode") dual-head SPECT camera (Infinia Hawkeye, GE Healthcare, United Kingdom), as a part of a standard 2-day-protocol as described in the European Association of Nuclear Medicine guidelines (45). Projection data were collected at 30 angles/head (in total $180^{\circ}$ ), and 30 seconds per angle for both the stress and rest studies. The rest studies were performed 4-7 days after the stress studies

\section{Study III}

All exams included in study III were standard of care CCTA exams obtained with a 128-slice dual source CT scanner (Definition Flash, Siemens, Forchheim, Germany) in mono-energetic dual source mode. The standard protocol was either a prospectively ECG-gated common spiral protocol (ref. mAs 306, 100kV, pitch 0.17 , rotation time $0.285 \mathrm{~s}$ ), a prospectively ECG-gated high-pitch protocol (ref. $\mathrm{mAs} 324,100 \mathrm{kV}$, pitch 3.4, rotation time $0.285 \mathrm{~s}$ ) or a retrospectively ECG-gated protocol (ref. mAs 306, $100 \mathrm{kV}$, pitch $0.17-0.38$ depending on the heart rate, rotation time 0.28 s). Nitroglycerin was routinely administered, as were beta blockers to patients with a heart rate $>65$ beats per minute (bpm).

\section{Study IV}

Four different CT-scanners were used in study IV. Standard protocols for the 64slice DSCT and 128 slice DSCT scanners have been described above. For the 192slice scanner, the standard protocol was a prospectively ECG-gated high-pitch protocol (ref. mAs $290,100 \mathrm{kV}$, pitch 3.2, rotation time $0.25 \mathrm{~s}$ ) for patients with a stable heart rate below $60 \mathrm{bpm}$. A retrospectively ECG-gated spiral protocol (ref. $\mathrm{mAs} 276,100 \mathrm{kV}$, pitch $0.15-0.34$, rotation time $0.25 \mathrm{~s}$ ) was used for patients with heart rate $>60 \mathrm{bpm}$ or irregular heart rhythm.

\section{Image analysis}

\section{Study I}

From each exam, two single $0.75 \mathrm{~mm}$ images covering parts of the left main coronary artery were selected: one from the systolic, low-dose phase at $35 \%$ of the 
R-R-interval, and one from the diastolic, full dose phase at $70 \%$ of the R-R-interval. The low-dose systolic image was duplicated and one copy subjected to post processing using a hardware based 2-D, non-linear adaptive noise reduction filter (SharpView ${ }^{\text {TM }}$ CT, Sharpview AB, Linköping, Sweden), resulting in three images per patient and a total of 108 images.

The quality of the selected images were evaluated using absolute VGA in a visual grading software package (ViewDEX 1.0, University of Gothenburg, Sweden) (89). Image quality was independently assessed by nine radiologists evaluating five different parameters, resulting in 972 image assessments and 4860 different parameter evaluations (Fig. 8). Prior to assessing the actual study material, each participating radiologist assessed 21 images for the purpose of training and calibration. The perceived image quality was graded using a five-point scale for five different criteria, three of which were applicable parts of the European Guidelines for assessment of image quality (70). Another two criteria were constructed along similar lines for the purpose of this study.

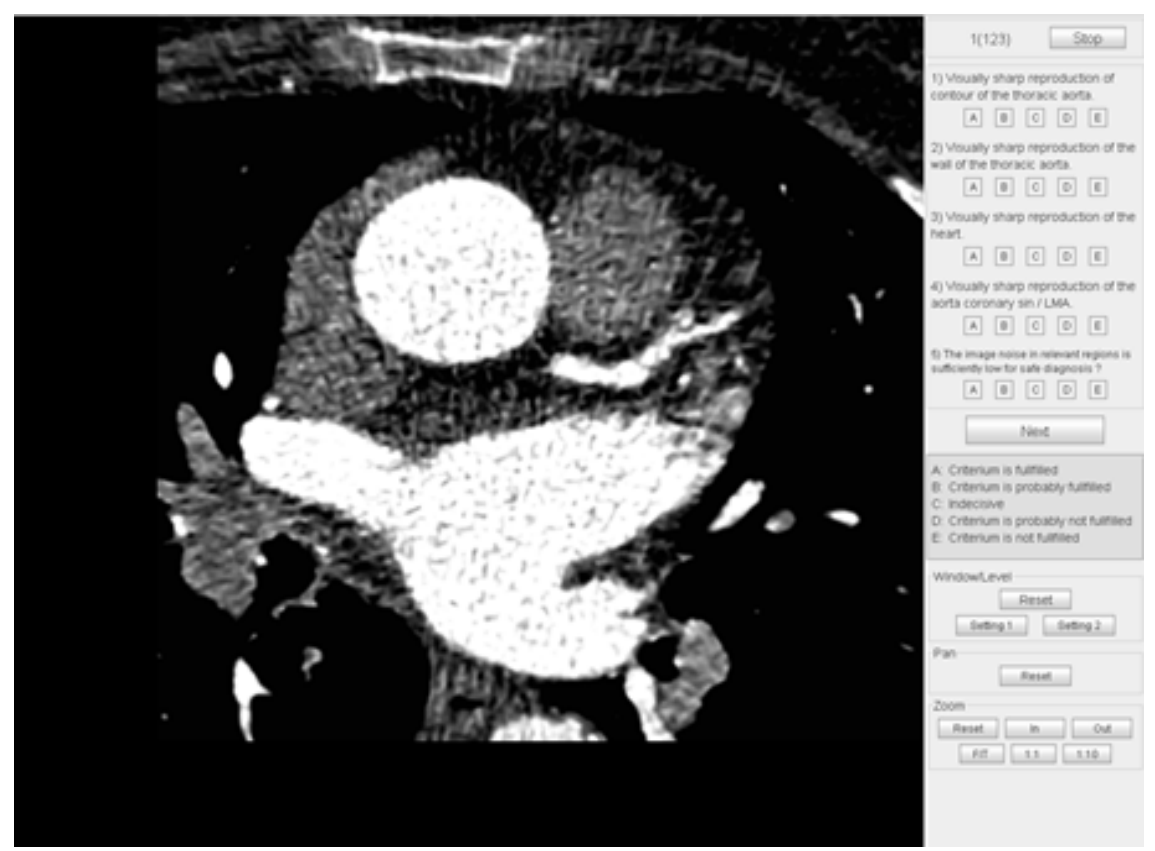

Fig. 8. Example from Viewdex 1.0 visual grading software package. Grading of each image quality criteria was performed using a 5 -grade scale.

Image noise was quantitatively evaluated by measuring the $\mathrm{HU}$-value and its standard deviation (SD) in the ascending and descending aorta (Fig. 9). 


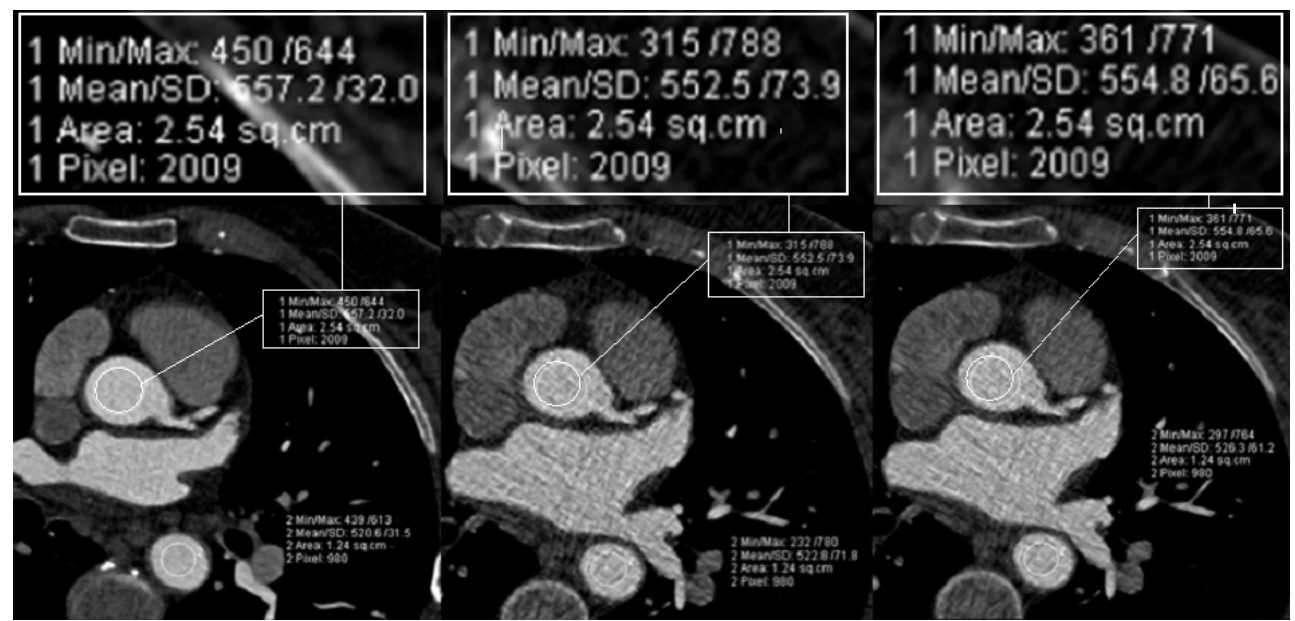

Fig. 9. Attenuation and noise level/SD measured in ascending aorta, with full-dose (left), reduced dose (mid) and reduced dose with applied noise reduction filter (right) respectively. The region of interest is enhanced for the purpose of clarity.

\section{Study II}

\section{Image analysis: CTP}

CT images were manually post-processed in order to align them as closely as possible with the AHA 17-segment model (90) and the corresponding SPECT, and to extract per segment blood flow values (Fig. 10).

2 Limits: $0.00 / 30710.00$ 2 Min/Max: $7.00 / 147.00$ 2 Mean/SD: $95.48 / 16.74$ 2 Area: 2.25 sq. $\mathrm{cm}$ 2 Pixel: 3783 2

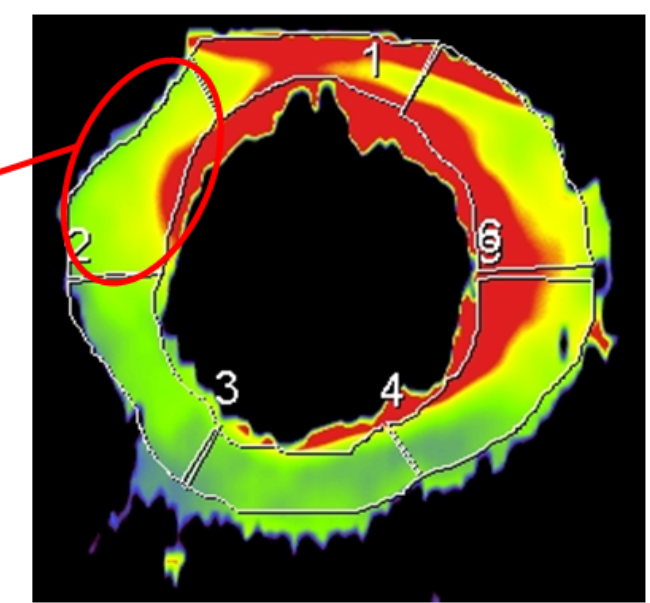

Fig. 10. Example of manual segmentation in one slice, with data on $\mathrm{min} / \mathrm{max} / \mathrm{mean}$ CTP blood flow. The left ventricular myocardium was manually divided into 10 similar slices and perfusion data was extracted for each AHA-segment in every slice. 
Eventually, a dedicated software was made available (Syngo Cardiac Function Analysis, prototype 2012-07-12, Siemens Healthcare, Germany), providing automated segmentation according to the AHA 17-segment model (Fig. 11). Calculation of per segment blood flow was based on the same image data as the manual method previously described.

\section{Image analysis SPECT}

The dataset of the SPECT scan was reconstructed using filtered back projection and the images were evaluated according to clinical routine, including the creation of an AHA 17-segment polar map image for comparison (Fig. 12). The stress SPECT results were stratified, with intensity values of $\geq 70 \%$ of maximum regarded as normal, values of $50-69 \%$ regarded as indeterminate and values of < $50 \%$ of the maximum intensity value regarded as pathological, in analogy with previously suggested stratification (45).

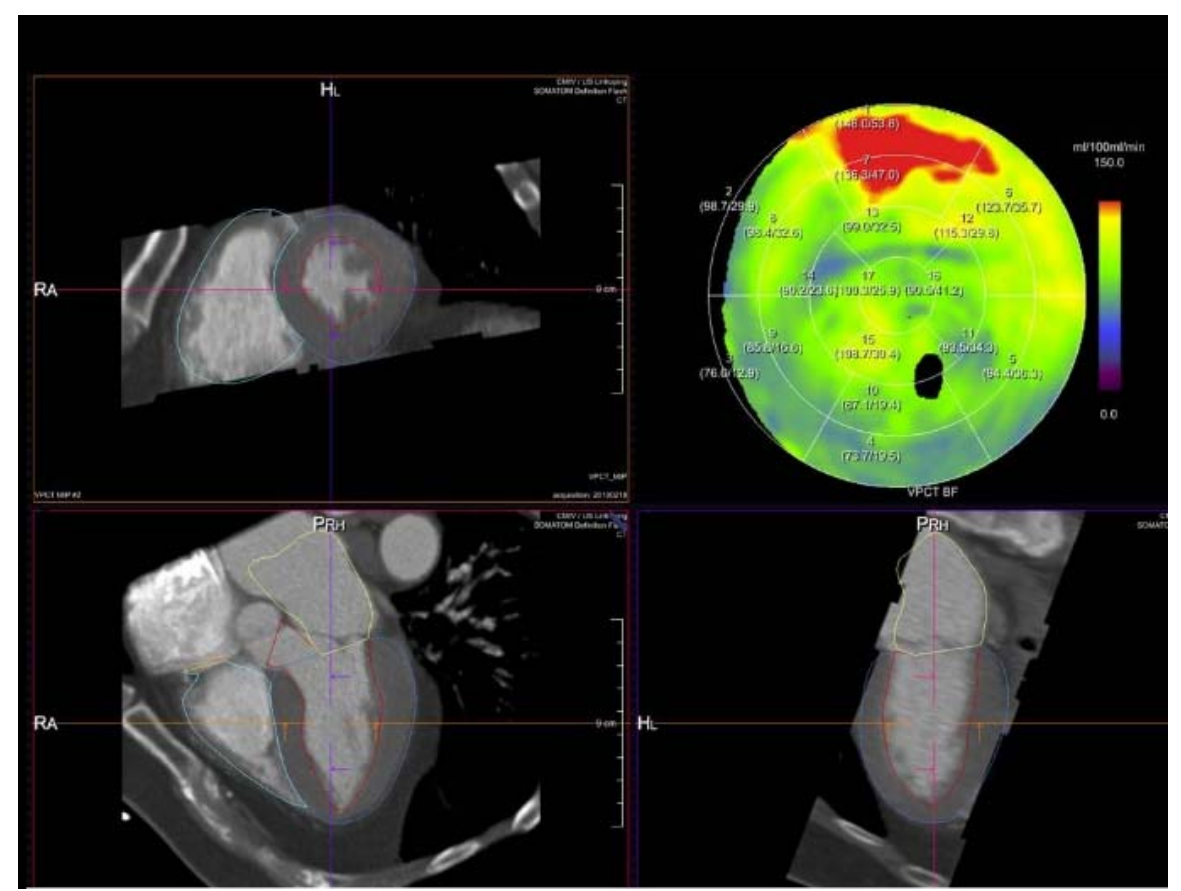

Fig. 11. Example of automated CT perfusion segmentation in the same patient as in Fig. 10. 


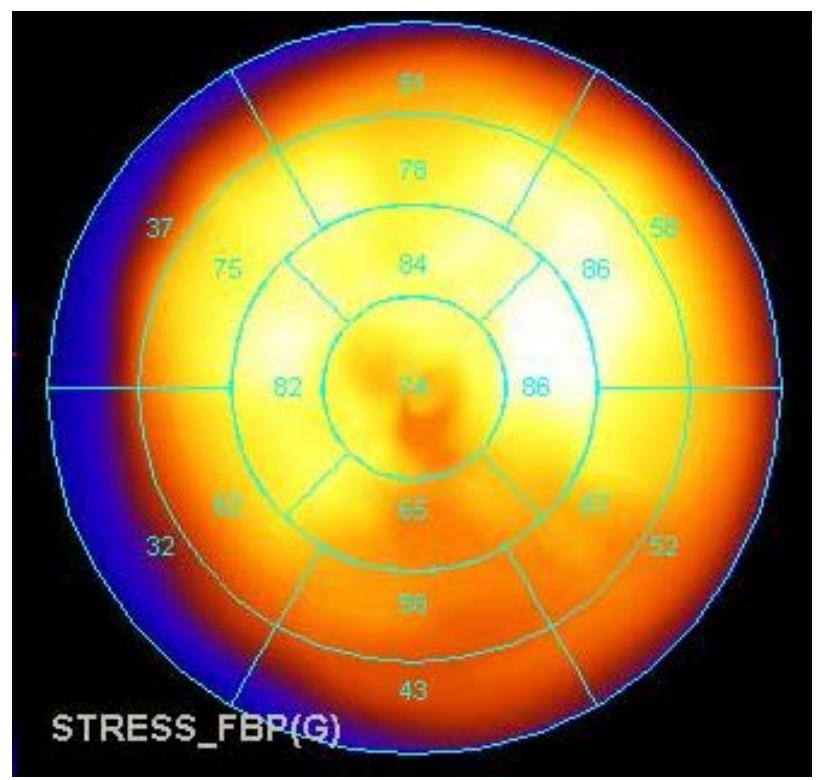

Fig. 12. Stress SPECT polar map in the same patient as in Fig. 10 and Fig. 11.

\section{Study III}

In study III, standard $0.75 \mathrm{~mm}$ CCTA data sets were transferred to a standalone workstation equipped with a research prototype software (Siemens cFFR, versions 1.4 and 1.7; Siemens Healthcare, not commercially available). Vessel centerlines and luminal contours were automatically generated by the software but had to be manually adjusted in most cases. Atherosclerotic/stenotic vascular segments were identified and their extent manually defined. Based on this input, a patient-specific 3-dimensional mesh was constructed by the software (Fig. 13).

Applying the principles of computational fluid dynamics, the cFFR algorithm simulated the coronary blood flow, including the hyperemic state usually induced by adenosine in invasive FFR measurements. Additional data incorporated into the algorithm included blood pressure, heart rate and left ventricular mass. The result was presented as a colour map of the coronary vascular tree, with the points of cFFR estimation being freely adjustable.

The cFFR colour map was compared to the corresponding ICA pressure guide wire image. The exact point of invFR-cFFR comparison was determined by an expert cardiac interventionist ( $>5000$ interventions), who was blinded to the cFFR segmentation process (Fig. 14). 


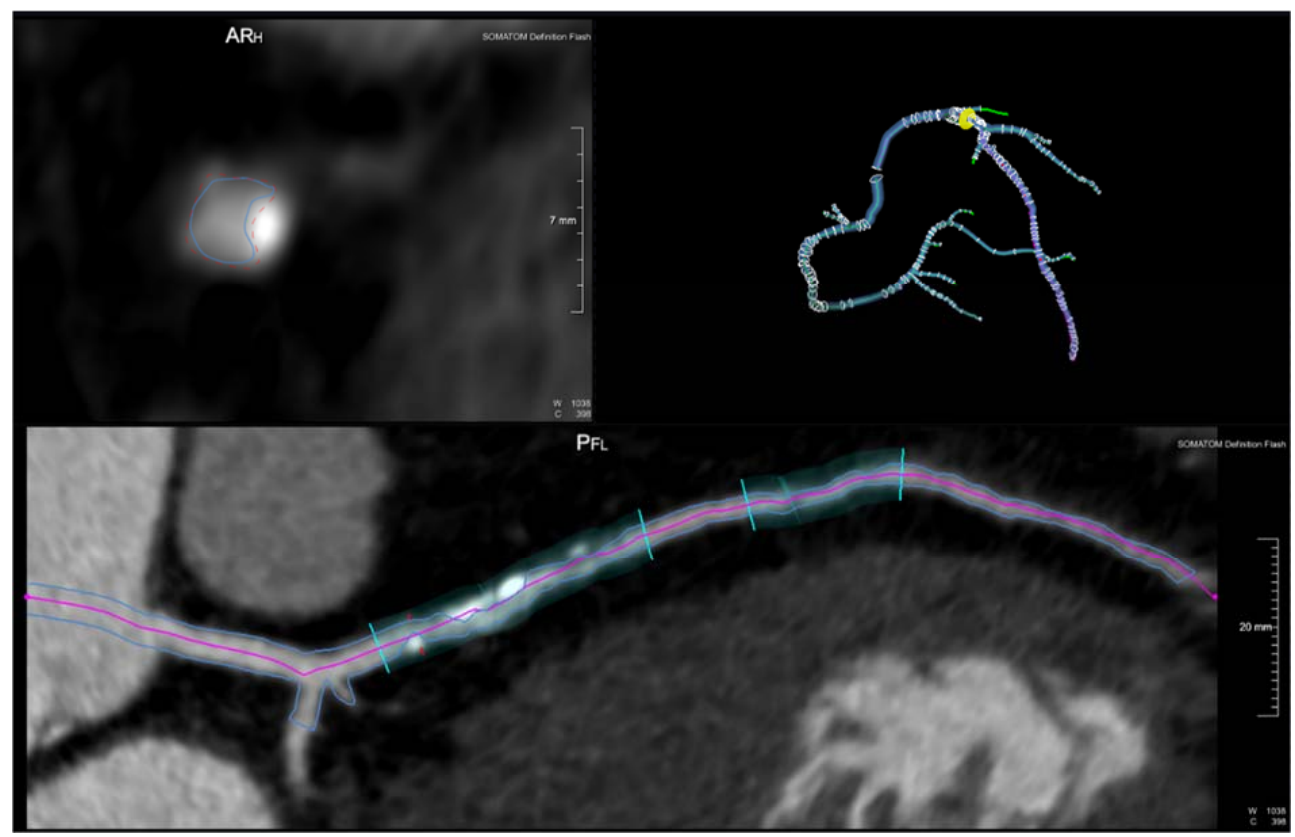

Fig. 13. Overview of segmentation process, with the left anterior descending artery (LAD) in cross-sectional and curved MPR view, and the 3-D coronary tree mesh. Stenotic segments are manually defined. Vessel contours are automatically outlined but can be manually adjusted.

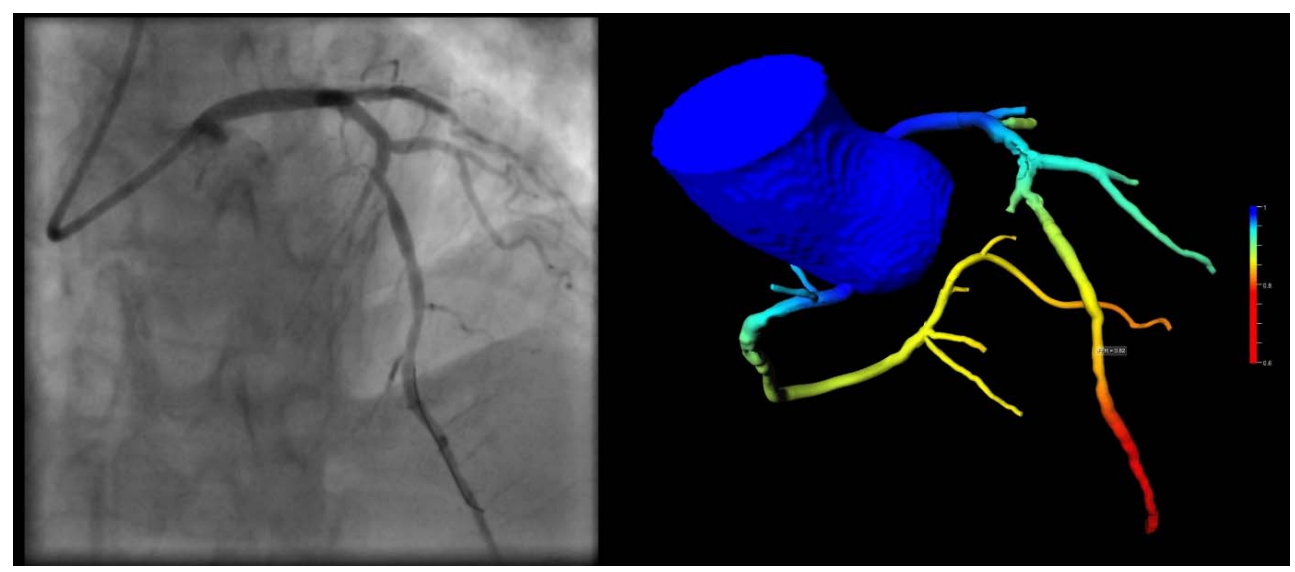

Fig. 14. Left: Angiographic image from the same patient as in Fig. 13, with pressure guide wire in the left anterior descending coronary artery (LAD). FFR $=0.81$. Right: Corresponding cFFR colour map with cFFR $=0.82$.

The time needed for the cFFR post-processing procedure was evaluated in a series of 11 additional cases. 


\section{Study IV}

The basis for study IV was the clinical CCTA results, as reported to the SWEDEHEART registry. However, as the SWEDEHEART registry does not record the presence or absence of non-significant atherosclerotic changes in the coronary arteries, all 1370 CCTA studies initially included were re-evaluated by a qualified thoracic radiologist and the presence of non-obstructive CAD was confirmed or negated (Fig.15). No re-evaluation of already reported obstructive CAD was made.

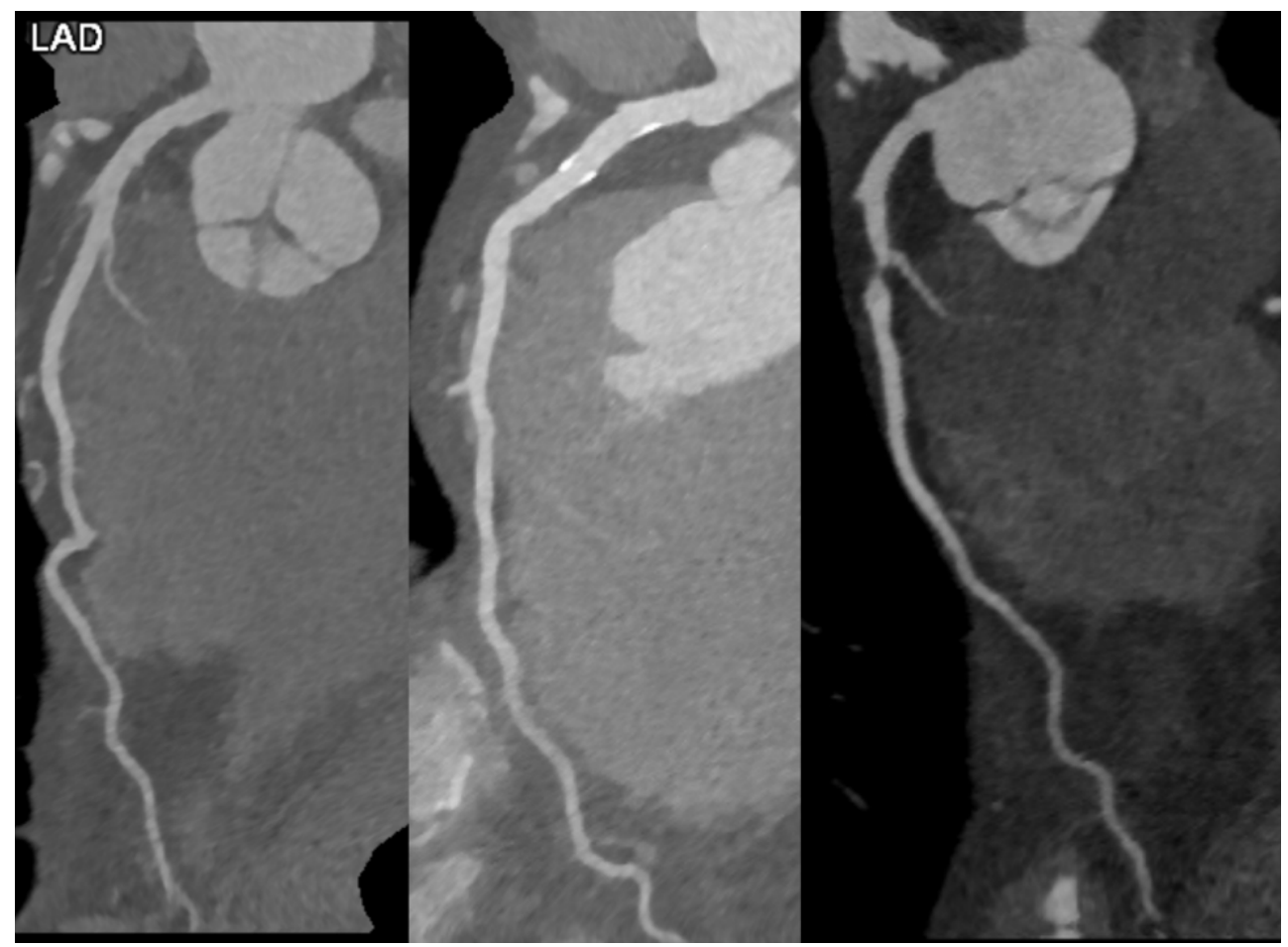

Fig. 15. Left anterior descending coronary artery (LAD) in three different patients. Left: Normal vessel. Mid: Mild atheromatosis. Right: Proximal stenosis 


\section{Statistical analysis}

\section{Study I}

Basic biometrical data on age and body weight was presented with mean and $\mathrm{min} / \mathrm{max}$ values. The results of the visual grading were analysed using ordinal logistic regression (91), controlling for patient and observer identity. HU-values in the ascending and descending aorta were evaluated with Student's T-test.

\section{Study II}

Biometrical data on age, sex, body weight, body length and body mass index (BMI) were presented individually for each of the participating patients, and the mean and $\mathrm{min} / \mathrm{max}$ values for the whole group were also reported. CTP for each segment was normalised according to the mean blood flow in the segments that were considered normal on SPECT (signal intensity $\geq 70 \%$ ) for each particular patient. The correlation between SPECT intensity values and the manually and automatically obtained CTP percentages was calculated for each patient using repeated measures analysis of variance (ANOVA). The results were presented as a correlation coefficient based on the average result obtained in all 8 patients, with a confidence interval of 0.95 .

The correlation between manually and automatically obtained per segment blood flow values was also calculated using ANOVA, followed by Duncan's post hoc test. The difference was further tested using Wilcoxon's matched pair test. In addition, the average all-segment global blood flow (taken as the sum of all segment blood flow values divided by 17) was calculated for both manually and automatically obtained values for each patient, and compared using Student's Ttest.

For this thesis, Spearman's rank correlation and the Intraclass Correlation Coefficient (ICC) were also calculated for the comparison between manual and automated segmentation.

\section{Study III}

Biometrical data was presented with mean, median and $\min / \max$ values. The agreement between cFFR and invFFR was expressed as an ICC, and the correlation as a Spearman's Rank correlation coefficient. A Bland-Altman plot displaying bias and limits of agreement was constructed. Sensitivity, specificity, positive predictive value, negative predictive value and accuracy of cFFR in predicting significant 
stenosis (defined from the invasive procedure as both FFR $\leq 0.80$ and FFR $\leq 0.75$ ) were calculated per-vessel as well as per-patient, using invFFR as the reference. Inter- and intraobserver reproducibility measurements on the severity of the stenosis in terms of the smallest diameter was performed in a total of 10 cases. The results were expressed as an ICC.

\section{Study IV}

Continuous variables were presented as median and inter-quartile range (IQR). Categorical variables were presented as numbers and percentages. Differences between the three groups (normal coronary arteries, non-obstructive CAD or obstructive CAD) were evaluated with Kruskal-Wallis one-way ANOVA by ranks as appropriate for continuous variables, and $\chi^{2}$-test for categorical variables. Fischer's exact test was used in case of very few $(n<5)$ outcome values.

A time-to-event curve for obstructive CAD vs. non-obstructive CAD and normal coronary arteries were drawn using the Kaplan-Meier method and further analysed with the $\log$ rank test. A separate analysis was also performed for normal coronary arteries vs. non-obstructive CAD. Multivariate analysis for classical risk factors and CCTA findings was performed using Cox proportional hazard regression with backward elimination.

The three-year incidence of MACE and readmission due to stable angina pectoris or chest pain was calculated for patients with a follow up period of three years or more $(n=655)$. Differences between groups were calculated with the combined groups of normal vessels and non-obstructive CAD versus the group with obstructive CAD, using the $\chi^{2}$-test and Fischer's exact test. 



\section{RESULTS}

\section{Study I}

The results of the visual grading are summarised for each criterion in Fig. 16. For all five criteria, there was a significant improvement in perceived image quality when comparing post-processed low-dose images with low-dose images without post-processing ( $\mathrm{p}<0.001$ except criterion 1 where $\mathrm{p}<0.01$ ). However, comparing full dose images with post-processed low-dose images resulted in a considerably larger, more significant $(\mathrm{p}<0.001)$ difference for all image criteria.

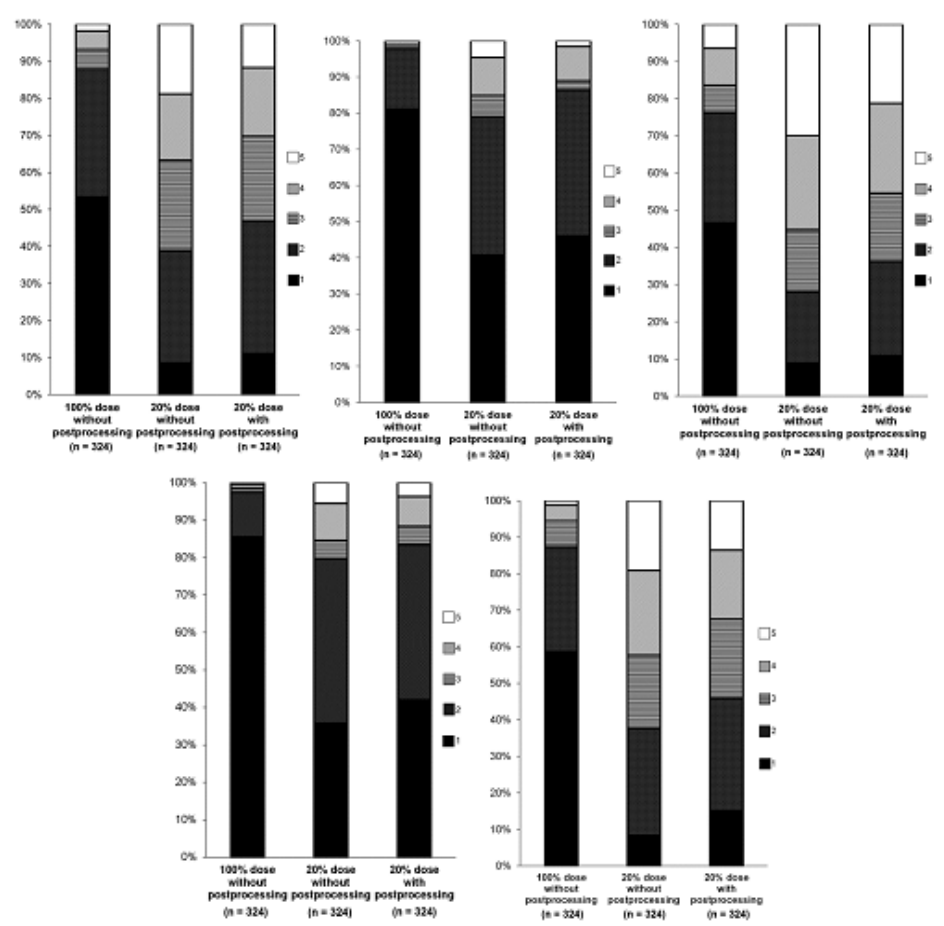

Fig. 16. Results for reproduction of the thoracic aorta, thoracic aortic wall, the heart and the left main coronary artery respectively. Criterion 5 pertains to the overall image quality

Applying the 2-D noise reduction filter to the low-dose images reduced the average standard deviation of the mean HU-value from 70.5 to 59.5 in the ascending aorta $(\mathrm{p}<0.001)$, and from 67.2 to 55.8 in the descending aorta $(p<0.001)$. The average standard deviation in the full-dose images was 35.2 in the ascending aorta and 34.6 in the descending aorta. 
Results

\section{Study II}

Of the eight patients to be analysed, five had a total of 21 segments where, due to limited coverage, less than $50 \%$ of the estimated volume was within the imaging slab. These segments, which mainly involved the anterior and antero-lateral walls, were excluded from the analysis. However, 115 out of 136 segments (85\%) were still deemed available for analysis on both CTP and SPECT. Of these 115 segments, 50 were considered "normal", with a signal intensity of $\geq 70 \%$ of the $\max$ intensity value for each respective patient. The number of segments classified as "normal" varied between 1 and 8 per patient.

CTP showed a positive correlation with SPECT data with both manual and automated segmentation, with correlation coefficients of 0.38 and 0.41 respectively $(p<0.001)$. There was no significant difference between the correlation coefficients of the manual and automated segmentation.

The mean, manually obtained global CTP blood flow value was $127 \pm 39$ $\mathrm{mL} / 100 \mathrm{ml}$ tissue/min and the mean, automatically obtained global blood flow value was $132 \pm 43 \mathrm{ml} / 100 \mathrm{~mL}$ tissue/min. The mean CTP value for all normal (on SPECT) segments in the study group was $131 \pm 38$ and $141 \pm 40 \mathrm{ml} / 100 \mathrm{ml}$ tissue/min for manual and automatic segmentation respectively. The mean per patient CTP blood flow in normal segments on SPECT ranged from 94-183 $\mathrm{ml} / 100 \mathrm{ml}$ tissue/min for manual segmentation, and 104-196 ml/100 ml tissue/min for automated segmentation. Further data on the mean and range for normal segments in each individual patient (with automatic segmentation) are presented in Fig 17.

The Spearman rank correlation coefficient between manual and automatic segmentation was $\rho=0.88(\mathrm{p}<0.001)$ and the ICC was 0.93 .

The global variation in blood flow between all segments (with automatic segmentation) is illustrated in Fig. 18. The total variation is similar for both segmentation methods. 


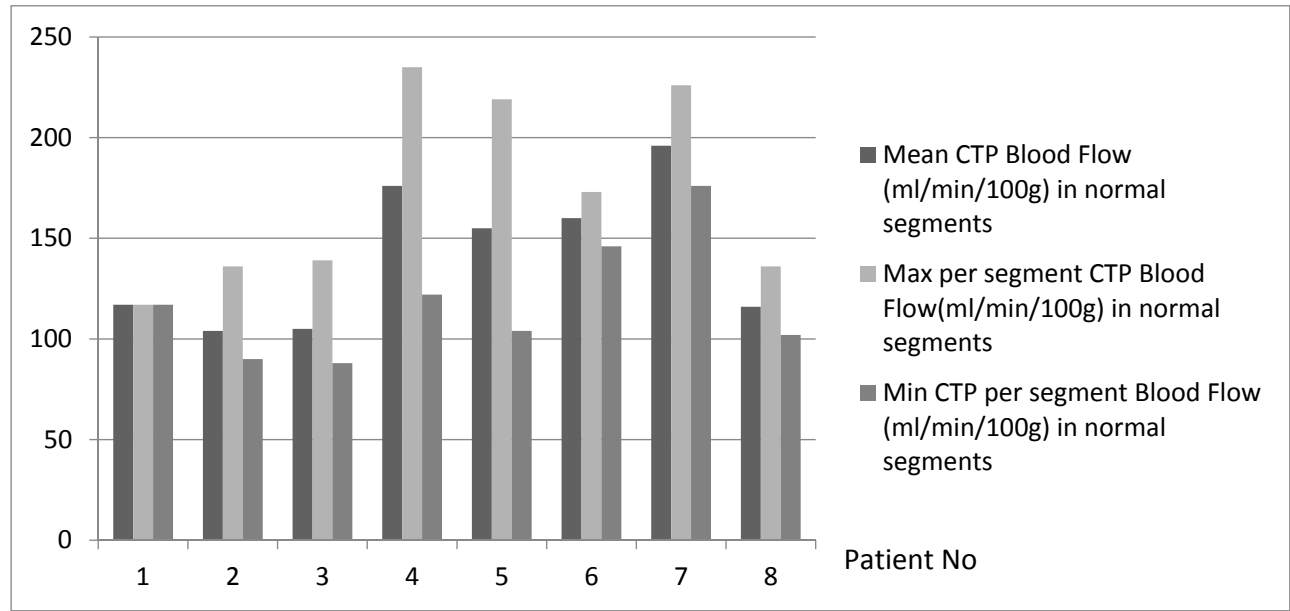

Fig. 17. Stress CTP blood flow values (mean $/ \mathrm{max} / \mathrm{min}$ ) in the normal segments $(\geq 70 \%$ uptake on stress SPECT) for each individual patient. Automatic segmentation.

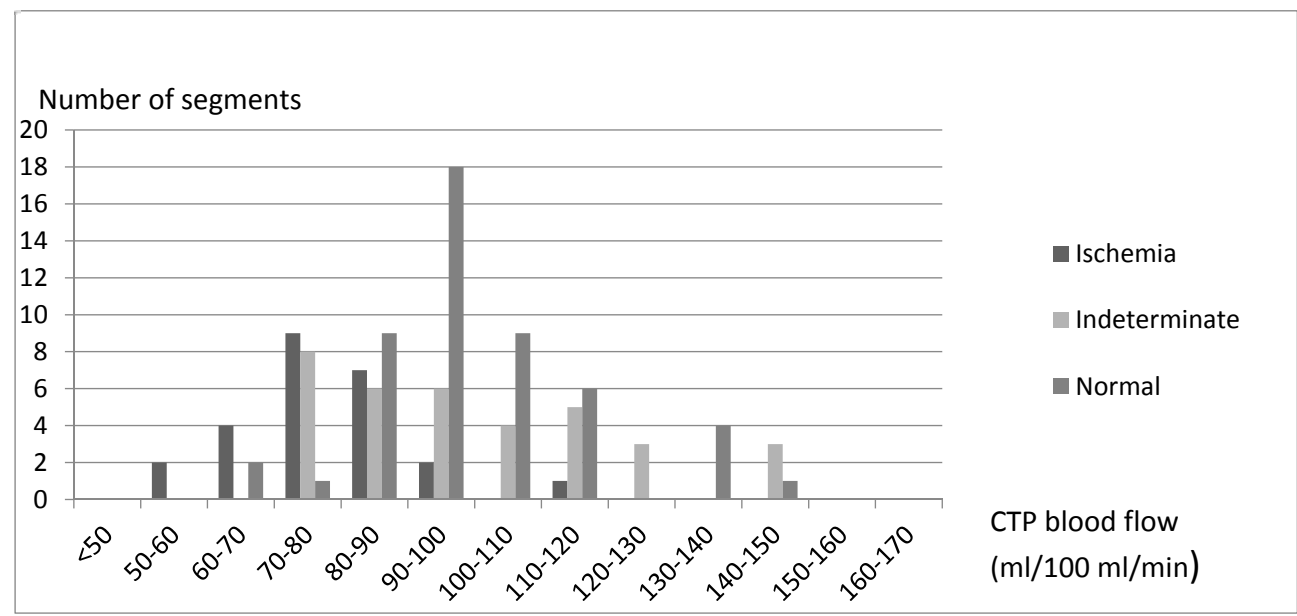

Fig. 18. CTP blood flow values presented as a percentage of the average CTP blood flow value of all segments with normal SPECT, and divided into normal ( $\geq 70 \%$ uptake on stress SPECT), indeterminate $(50-70 \%)$ or pathological $(\leq 50 \%)$ categories depending on the SPECT result for each respective segment.

\section{Study III}

The mean cFFR value for the whole group was 0.81 , and the corresponding mean invFFR value was 0.84 . The agreement between invFFR and cFFR expressed as an ICC was $0.73(p<0.001)$. The Spearman's correlation coefficient was $\rho=0.77$ $(\mathrm{p}<0.001)$ (Fig. 19). 
Results

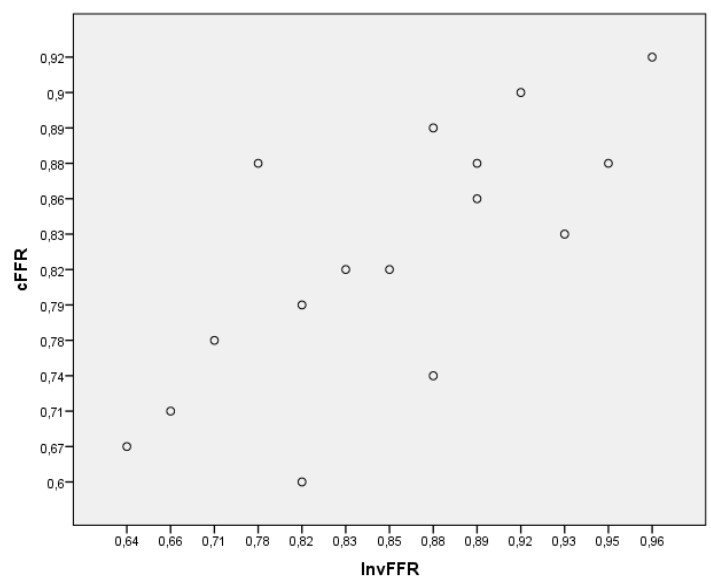

Fig. 19. Scatterplot showing the relation between cFFR and InvFFR values. Spearman's rank correlation $\rho=0.77$.

The Bland-Altman analysis, as presented in Fig. 20, showed a low systemic bias and relatively tight limits of agreement.

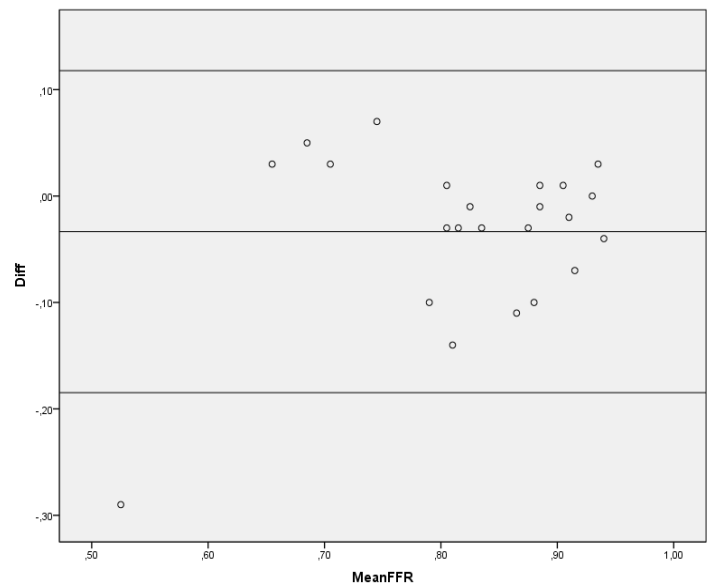

Fig. 20 Bland-Altman plot comparing invasively obtained fractional flow reserve (invFFR) and CT-based fractional flow reserve (cFFR) on a per-lesion basis. The systematic bias is relatively low ( $95 \%$ limits of agreement are -0.18 to 0.12$)$. 
The cFFR sensitivity, specificity and the positive and negative predictive values for significant stenosis as defined by invFFR $\leq 0.80$ and invFFR $\leq 0.75$ are presented in table 1.

$\begin{array}{cccc}\text { FFR } \leq 0.80 & \text { FFR } \leq 0.80 & \text { FFR } \leq 0.75 & \text { FFR } \leq 0.75 \\ \text { per lesion } & \text { per pat. } & \text { per lesion } & \text { per pat. } \\ (n=23) & (n=21) & (n=23) & (n=21)\end{array}$

\begin{tabular}{l|llll|}
\hline Sensitivity & 0.83 & 0.83 & 0.80 & 0.80 \\
Specificity & 0.76 & 0.80 & 0.89 & 0.88 \\
Positive predicitive value (PPV) & 0.56 & 0.63 & 0.67 & 0.67 \\
Negative predicitive value (NPV) & 0.93 & 0.93 & 0.94 & 0.93 \\
Accuracy & 0.78 & 0.81 & 0.81 & 0.86
\end{tabular}

Table 1: Results for CT-based fractional flow reserve (cFFR) in detecting significant stenosis, defined as both FFR $\leq 0.80$ and $\mathrm{FFR} \leq 0.75$.

The mean and median time required for the complete cFFR post processing procedure was 45 and 46 minutes respectively (range 34-61 minutes). The mean and median time required for cFFR computation once the semi-automated segmentation process was completed was $4 \mathrm{~min}$ and $16 \mathrm{sec}$, and $3 \mathrm{~min} 28 \mathrm{sec}$ respectively (range $2 \mathrm{~min} 10 \mathrm{sec}-12 \mathrm{~min}$ and $30 \mathrm{sec}$ ).

\section{Study IV}

The final study population consisted of 1205 patients (693 women and 512 men, $57.5 \%$ and $42.5 \%$ respectively) with a median age of 56 years and BMI of 26.0 $\mathrm{kg} / \mathrm{m}^{2}$. Maximum follow-up was 2724 days (7.5 years), with a median follow-up of 1121 (IQR 415-1793) days/3.1 years. Obstructive CAD was found in 177 patients (14.7\%), non-obstructive $\mathrm{CAD}$ in 360 patients $(29.9 \%)$ and normal coronary arteries in 668 patients $(55.4 \%)$. A total of $84 \mathrm{MACE}(47.5 \%)$ were recorded in the group with obstructive CAD on CCTA. The corresponding numbers for nonobstructive CAD and normal vessels were $9 \mathrm{MACE}(2.5 \%)$ and $5 \mathrm{MACE}(0.75 \%)$ respectively.

A total of 655 patients had a follow-up period of three years or more after CCTA. The incidence of a MACE during the three-year follow-up was $1.1 \%$ for patients with normal vessels on CCTA, $2.5 \%$ for patients with non-obstructive $\mathrm{CAD}$ and $42.7 \%$ for patients with obstructive CAD $(\mathrm{p}<0.001)$. 
Results

Kaplan-Meier survival curves over 7.5 years for MACE in obstructive CAD vs. normal coronary arteries and non-obstructive CAD, and for normal coronary arteries vs. non-obstructive CAD are shown in Fig. 21. The log rank test for differences between groups showed a $\chi^{2}$-value of $282.487(\mathrm{p}<0.001)$ for obstructive CAD vs. normal coronary arteries and non-obstructive CAD, and $3.052(p=0.081)$ for normal coronary arteries vs. non-obstructive CAD.
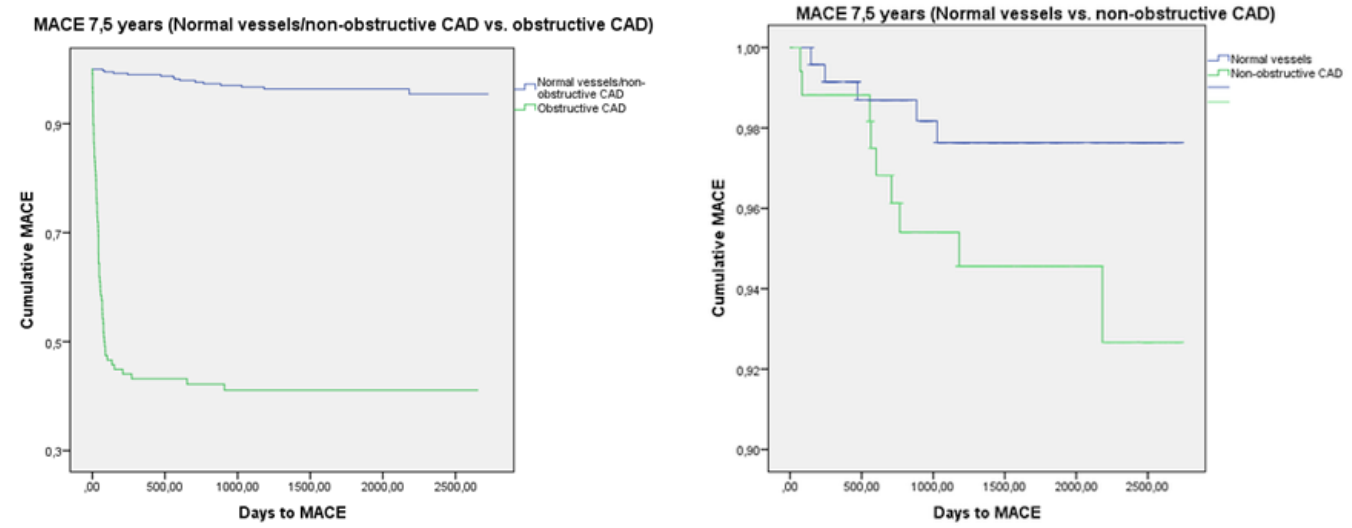

Fig. 21: Kaplan-Meier plots for MACE-free survival over 7.5 years.

Left: Normal coronary vessels + non-obstructive CAD vs. obstructive CAD. Log rank: $\chi^{2}=$ 282.487, $<<0.001$. Right: Normal coronary vessels vs. non-obstructive CAD. Log rank: $\chi^{2}=3.052$, $\mathrm{p}=0.081$. MACE $=$ Major adverse cardiac event, $\mathrm{CAD}=$ Coronary artery disease.

Multivariate Cox regression analysis showed a hazard ratio (HR) of $5.13(95 \%$ C.I 1.03-25.43, $\mathrm{p}<0.05)$ for MACE among patients with non-obstructive CAD vs. normal coronary arteries and a HR of 151.40 (95\% C.I 37.03-619.08, p <0.001) for obstructive CAD vs. normal arteries. Beside CCTA findings, only male sex (HR 2.2, 95\% C.I 1.33-3.57, $\mathrm{p}<0.05$ ) and BMI (HR 1.1, 95\% C.I 1.33-3.57, p<0.05) were associated with MACE.

The three-year incidence of readmission for stable angina or chest pain after CCTA was 101/655 (15.4\%) for the whole group, and 32/372(8.6\%), 31/201 $(15.4 \%)$ and $38 / 82(46.3 \%)$ for normal coronary arteries, non-obstructive CAD and obstructive CAD respectively (Table 2 ). 


\begin{tabular}{l|ccccc}
$\begin{array}{l}\text { Outcome } \\
3 \text { years }\end{array}$ & $\begin{array}{c}\text { Total } \\
\mathrm{n}=655\end{array}$ & $\begin{array}{c}\text { Normal vessels } \\
\mathrm{n}=372\end{array}$ & $\begin{array}{c}\text { Non-obstructive } \\
\text { CAD, } \mathrm{n}=201\end{array}$ & $\begin{array}{c}\text { Obstructive } \\
\text { CAD, } \mathrm{n}=82\end{array}$ & $\mathrm{p}$-value \\
\hline MACE & $44(6.7 \%)$ & $4(1.1 \%)$ & $5(2.5 \%)$ & $35(42.7 \%)$ & $\mathrm{p}<0.001$ \\
Cardiac death & $0(0.0 \%)$ & $0(0.0 \%)$ & $0(0.0 \%)$ & $0(0.0 \%)$ & - \\
MI & $7(1.1 \%)$ & $2(0.5 \%)$ & $2(1.0 \%)$ & $3(3.7 \%)$ & $\mathrm{p}<0.05^{*}$ \\
Readm. UAP & $15(2.3 \%)$ & $2(0.5 \%)$ & $2(1.0 \%)$ & $11(13.4 \%)$ & $\mathrm{p}<0.001^{*}$ \\
Revasc. & $34(5.2 \%)$ & $1(0.3 \%)$ & $2(1.0 \%)$ & $31(37.8 \%)$ & $\mathrm{p}<0.001^{*}$ \\
Re-adm, other & & & & $18(22.0 \%)$ & $\mathrm{p}<0.001^{*}$ \\
Stable AP & $31(4.7 \%)$ & $3(0.8 \%)$ & $10(5.0 \%)$ & $20(24.4 \%)$ & $\mathrm{p}<0.001$ \\
Chest pain & $71(10.8 \%)$ & $29(7.8 \%)$ & $22(10.9 \%)$ & 20.001 \\
\hline
\end{tabular}

Table 2: Three-year incidence of major adverse cardiac events (MACE) and readmissions in patients with normal coronary arteries, non-obstructive CAD and obstructive CAD respectively. Some numerical overlap between the separate events and the compound MACE-parameter is present, since only one event per patient contributes to MACE. Differences between groups were calculated with the combined groups of normal vessels and non-obstructive CAD versus the group with obstructive CAD, using the $\chi^{2}$-test and Fischer's exact test $\left(^{*}\right)$.

$\mathrm{MI}=$ Myocardial infarction, $\mathrm{UAP}=$ Unstable angina pectoris, $\mathrm{AP}=$ Angina pectoris, $\mathrm{CAD}=$ Coronary artery disease, Readm. $=$ Readmission, Revasc. $=$ Revascularization.

All-cause death during the study period was limited to 12 cases $(1.0 \%)$, with $5 / 668(0.7 \%)$ in the group with normal vessels, 5/360 (1.4\%) in the group with non-obstructive CAD and $2 / 177(1.1 \%)$ in the group with obstructive coronary disease $(\mathrm{p}=0.558)$. Only one death was cardiac-related, while the majority (eight deaths) were related to cancer. There was no significant difference in all-cause death between the different groups. 
Results 


\section{DISCUSSION}

The core theme for this thesis has been the evaluation and improvement of the diagnostic capability of CCTA. Previous studies indicate that approximately $40 \%$ of all ICA in patients with suspected CAD show normal findings, thus leading to no further intervention (92,93). Data from the Swedish SCAAR registry indicate a similar percentage. This is unfortunate as ICA is an invasive, and thus expensive, technique that also carries with it a certain procedural risk. Hence, there are both medical and economical gain to be made by improving the diagnostic yield of CCTA and, where possible, reducing the number of unnecessary ICA.

Advanced CT applications such as CTP and cFFR might assist in the important triage process to invasive procedures by providing additional data beyond mere visualisation of the coronary arteries. One recent example is described in the PLATFORM study (94), where the use of cFFR (although from another vendor than used in study III) was shown to be able to reduce the number of unnecessary ICA by $83 \%$, while retaining the same number of revascularisations and without increasing the 90 -day risk of MACE.

Apart from CTP and cFFR, image improvement as outlined in study I may also play a role in improving CCTA diagnostic yield without increasing the radiation dose. Lastly, the epidemiological perspective of study IV contributes to the general knowledge on how to interpret CCTA results from a long-term prognostic point of view.

\section{Aspects on patient selection}

\section{Study I}

Patient selection in study I was uncontroversial as inclusion was consecutive during one randomly chosen month. Exclusions were only due to the fact that some image material did not conform to the study protocol. Since focus was on image quality only, the indication for the exam was not a concern.

\section{Ethical aspects of Study I}

Study I was performed without formal assessment in the Regional ethical review board. At the time, this was regarded as acceptable as the focus of the study was on 


\section{Discussion}

evaluation of image quality only. Only anonymised, single images were used, and there was no medical evaluation of the image material. The patient data needed was very limited. Today, in most situations an assessment from the Regional ethical review board provides evidence that an independent review of possible ethical problems has been performed.

\section{Study II}

In study II, patient selection was more complex, as the participating patients were selected specifically for their combination of previous myocardial infarction and PCI with at least one untreated significant stenosis, thus introducing significant selection bias. However, this was very early in the development of dynamic CTP and the intention was to maximise the number of potential ischemic lesions in a small pilot study, and to explore the possibility of differentiating between ischemic and infarcted myocardial tissue.

\section{Study III}

In study III, the main inclusion criterion was clinical CCTA with subsequent ICA and FFR-measurement within 120 days, and a total of 63 consecutive patients were identified. In order to avoid vendor- or model-specific variations, the inclusion time-frame was selected so that all CCTA were performed on one specific scanner.

All patients had findings on CCTA that warranted further investigation with ICA. Also, in a clinical setting FFR is mainly used on border-line stenoses as a tool for determining the need for revascularisation. Stenoses that are clearly significant, and light atheromatous changes are rarely investigated with this method. Hence, the risk of selection bias needs to be considered in relation to the study results.

\section{Study IV}

In study IV, the study cohort was chosen from a total of 3038 CCTA exams performed between 2007 and 2014. All exams in patients with known CAD or other cardiac disease were excluded, as were all exams with suboptimal image quality. Thus, the patient selection process was similar to several other studies with similar objectives (24-27,95-97). 


\section{Aspects on image acquisition and evaluation}

\section{Study I}

Study I utilised high and low dose/quality images captured from the same clinical exam, which is a novel approach that we have not been able to find elsewhere. Through the use of retrospective ECG-gating, images covering the 35-75\% segment of the cardiac R-R-interval were available. ECG-regulated dose modulation ensured that the 35\% phase in most cases was captured with a reduced dose, and that the $40-75 \%$ phases were captured with the full dose. Thus the $35 \%$ phase and the $70 \%$ phases were selected for evaluation and comparison. Nine cases were excluded as the $35 \%$ phase was captured with full dose, possibly as a result of a slightly irregular heart rhythm.

However, comparison between systolic and diastolic images may be problematic as the flow in the coronary arteries (and probably also the vessel diameter) varies throughout the cardiac cycle (15). Thus, the fact that the full-dose images were acquired during the diastolic phase and the low-dose images during the systolic phase could affect the image quality rating, probably to the detriment of the low-dose images. Low-dose images obtained during the systolic phase might also be more prone to motion artefacts than the full-dose images obtained during the diastolic phase. This has not been compensated for and may thus constitute a systematic error. However, it does not affect the comparison between low-dose images with and without post-processing.

Due to limitations in the VGA software, only single images were assessed, thus creating an unrealistic evaluation situation. Later software releases have addressed this issue.

\section{Study II}

In study II a dynamic stress CTP image acquisition was performed and estimated quantitative CTP blood flow compared to semi-quantitative stress SPECT. In retrospect, had rest CTP been added, a better differentiation between ischemic and infarcted areas could have been facilitated. The reason for this omission was concern about radiation dose, as the study patients were already subjected to stress CTP and rest/stress SPECT. Except for Ho et al (58), most other studies on dynamic CTP have also abstained from rest CTP, for similar reasons.

The effective CTP scan length was only $7.3 \mathrm{~cm}$ along the long axis of the body, which in many cases proved inadequate for covering the whole heart. As previously 


\section{Discussion}

stated, four exams were excluded because of this, and several were partially affected. This seems to be a common problem, which is described by other authors as well $(57,61)$. The use of Adenosine as an agent for vasodilatation and thus flow redistribution may have contributed to this problem by increasing respiratory drive (98), hence increasing chest motion and the risk of motion artefacts. Secondary effects such as tachycardia and increased blood flow velocity $(99,100)$ may have contributed to a shortening of the time taken for the bolus front to reach the aorta as compared with the test bolus, thus possibly causing the timing errors that led to the exclusion of a further four cases. The use of receptor selective agents, such as regadenoson, could possibly have reduced the frequency of excessive respiratory drive and resulted in fewer exclusions due to motion artefacts $(101,102)$. The timing problem was solved by shortening the estimated delay time from contrast infusion to image acquisition by three seconds.

The investigators were not blinded to the results from the SPECT, or from previous ICA/PCI. Although blinding would have been preferable, it was not regarded as essential in this early study on dynamic CTP, as the objective was to establish whether the use of dynamic CTP for myocardial perfusion imaging was at all feasible. The rather primitive and time-consuming manual segmentation process that was used initially was due to the lack of software able to present per-segment results according to the AHA 17-segment model (90), something that was considered essential when quantitatively evaluating estimated CTP blood flow values vs. relative SPECT signal intensity. At a later stage, the vendor made available a prototype software with this functionality, which greatly simplified the process. Thus, our focus was different to that of most other studies comparing dynamic CTP with SPECT or cMR, as the most common approach is that of visual detection of perfusion defects (58-60). However, a study by Wang et al (103) did a similar type of comparison albeit with a different patient group.

\section{Study III}

Study III used clinical, standard-of-care CCTA exams only, with $0.75 \mathrm{~mm}$ CCTA datasets being used for the cFFR segmentation process. At this early stage of cFFR stenosis evaluation, it was considered essential to use only ICA/FFR exams where the exact location of the pressure guide wire was depicted, as reference. Written descriptions or manual drawings, such as are commonly used in clinical routine, were not considered precise enough for exact comparison between cFFR and invFFR. Thus, the point of cFFR-invFFR comparison on the cFFR colour map was determined from the pressure guide wire position in the corresponding ICA. 
The employment of an expert cardiac interventionist for this task minimised the risk of misinterpretation of the ICA images. A similar strategy seems to have been used by other early investigators $(104,105)$.

\section{Study IV}

Study IV was not an experimental study, but rather conceived as an epidemiologic study on the prognostic value of clinical CCTA. Thus, the main focus was on risk and survival analysis.

Study patients were consecutively included in a clinical setting, thereby reflecting real-life patients. All exams were performed according to current guidelines, using a 64 slice DSCT or better. Unlike other similar studies, which to a large extent rely on telephone interviewing and patient files for follow-up, this study was based almost entirely on registry data (from the SWEDEHEART/SCAAR registries). However, all 1370 initially included exams were re-evaluated regarding the presence or absence of non-obstructive atheromatosis, since this information is not registered in the SWEDEHEART data base.

For outcome analysis, a MACE parameter was constructed, including cardiac death, myocardial infarction, admission due to unstable angina pectoris (UAP) and revascularisation. Unlike most other similar studies elective revascularisation was included in the MACE definition. The reasoning behind this decision was that, even though elective, most revascularisations were performed as a direct result of the CCTA findings. Also, in a clinical setting, it may be difficult to differentiate between elective, semi-elective and acute procedures.

\section{Aspects on the results}

\section{Study I}

The aim of study I was to investigate whether the use of a 2-D, non-linear adaptive noise reduction filter could improve image quality in CCTA. The results showed that there was a significant improvement of the perceived image quality of lowdose images when the filter was applied, even though the improvement was small compared to the image quality of the corresponding diastolic full-dose images. Thus, the filtering was not able to compensate for the large dose reduction. Also, image noise expressed as the average standard deviation of the HU-values in the 


\section{Discussion}

ascending and descending aorta was significantly reduced, thus providing a more quantitative indication of the value of additional image filtering.

In spite of the improvement in perceived image quality, the results did not actually show that the filter can be used to lower the dose while retaining image quality. Such proof would require a more systematic approach, with image acquisition at several different dose-levels for each subject. However, a later study, utilising the same patient material, statistically deduced that a more realistic dose reduction of $16-26 \%$ was feasible using this particular filter (106).

Clinical studies on adaptive filtering are scarce and presently, research interest seems to be more focused on iterative reconstruction techniques as a dose saving measure. As far as we know, there are no other studies performed on adaptive filters in cardiac imaging, but Borgen et al (107) used a comparable filter solution (among others) and a dose reduction of $50 \%$ in a prospective study on abdominal imaging, with similar results.

\section{Study II}

The primary aim of study II was to evaluate the variation in adenosine stress dynamic CTP blood flow as compared to ${ }^{99 \mathrm{~m}} \mathrm{Tc}$ SPECT. The results showed a positive but weak correlation between quantitatively measured CTP and semiquantitative SPECT of $\mathrm{r}=0.38$ and $\mathrm{r}=0.41$ for manual and automated CTP segmentation respectively, as compared to $r=0.64$ by Wang et al (103). There was also a surprisingly large variation in estimated stress CTP in segments that all could be considered normal with SPECT. As shown in fig. 18, the same absolute CTP blood flow value could be interpreted as normal, intermediate or pathological, depending on the patient. Based on these findings, we concluded that it is difficult to define a absolute cut-off value for normal vs. hypoperfused myocardium on the basis of comparison with SPECT.

There are several potential explanations for this result. One is the fundamentally different mechanisms utilised by each method, presumably making direct comparisons difficult. Another possible explanation is the presence of extensive CAD in the patient group. Although none of the patients were described as having three-vessel disease, the possibility of a general decrease in SPECT signal intensity due to extensive CAD must be taken into consideration. However, Wang et al (103) describe a mean CTP blood flow of $142.9 \pm 30.6 \mathrm{~mL} / 100 \mathrm{~mL}$ tissue/min in normal segments (on SPECT) in a population with suspected CAD, while Ho et al (58) describe $121 \pm 31 \mathrm{~mL} / 100 \mathrm{~mL}$ tissue/min and Kim et al (59) $113.2 \pm 26$ in normal segments, thus placing our corresponding results of $131 \pm 38$ and $141 \pm 40 \mathrm{~mL} / 100 \mathrm{~mL}$ tissue/min for manual and automated segmentation well 
into the normal range as defined by these three studies. Also, in a relatively recent study by Bamberg et al (60), the cut-off point for differentiation between normal and ischemic myocardium was determined to be $0.88 \mathrm{~mL} / 100 \mathrm{~mL}$ tissue $/ \mathrm{min}$.

All of these results are significantly lower than results in experimental studies using ${ }^{15} \mathrm{O}$-water and ${ }^{13} \mathrm{~N}$ - ammonia positron emission tomography (PET), where the average Adenosine stress blood flow was 263 and $273 \mathrm{~mL} / 100 \mathrm{~mL}$ tissue/min respectively (108). The reason is not entirely clear but Rossi et al have shown that similar CTP blood flow values can be recorded in pigs by administering a much larger Adenosine dose than is used in clinical practice, thereby increasing regional myocardial blood flow (109).

Thus, quantitative comparison between dynamic CTP and SPECT is difficult to perform. Most other comparative studies $(58-60,103)$ have used a qualitative approach, with focus on the visual detection of perfusion defects as compared to the reference method. The results of these studies have also been more encouraging, with sensitivity and specificity for perfusion defects in relation to SPECT of $0.83-0.85$ and $0.78-0.92$ respectively $(58,103)$. In future studies this approach could possibly yield more clinically useful results.

The secondary aim of the study was to compare per segment myocardial blood flow values obtained by manual and automatic segmentation. For this comparison, the resulting between-segment difference in blood flow was small and nonsignificant. Calculation of Spearman rank correlation coefficient and Intraclass Correlation Coefficient showed excellent results, indicating that both methods were equally useful.

\section{Study III}

The aim of study III was to evaluate the accuracy of cFFR, as compared to invFFR.

The results showed a rather good concordance with invFFR, with a Spearman rank correlation coefficient of $\rho=0.77(\mathrm{p}<0.001)$ and ICC $=0.73(\mathrm{p}<0.001)$. Although a small study, these results are in the same range as the results obtained by other authors using the same software $(104,105)$, and they are also similar to those obtained in the DeFACTO and NXT studies (110,111), where similar software from another vendor was used. Maybe most importantly, the high negative predictive value of 0.93-0.94 (depending on the cut-off limit for significant stenosis) suggests that cFFR has the potential to be very useful in the triage to invasive angiography, possibly reducing the need for further invasive investigation in a number of patients.

The average time of approximately 45 minutes required for the cFFR analysis was also in line with the results recorded by Coenen et al (105). Although the 


\section{Discussion}

comparatively short processing time in itself facilitates an efficient patient flow compared to other current solutions, newer algorithms and even faster hardware are expected to make the processing close to instantaneous in the near future.

\section{Study IV}

The aim of study IV was to evaluate the long-term outcome after CCTA in patients without known CAD. The maximum follow-up time of 7.5 years was unusually long in this context, although the median follow up time of 3.1 years was more in line with earlier studies. Only three patients $(0.2 \%)$ were lost to follow-up, due to not having a Swedish personal identity number, as compared to approximately 5$15 \%$ in several other studies $(25,27,28)$.

A total of $85.3 \%(n=1028)$ of the exams included did not indicate obstructive CAD, and the results for this group showed a very low risk for MACE. In fact, only nine cases $(1.6 \%)$ of MACE were recorded during three-year follow-up in patients without obstructive CAD ( $\mathrm{n}=573$ ), and for the whole study period of up to 7.5 years the corresponding number was 14 cases $(1.4 \%)$. However, even in patients without obstructive CAD, the differentiation between normal coronary arteries and non-obstructive atheromatosis on CCTA seems important as the multivariate Cox regression analysis showed a HR of 5.13 for non-obstructive CAD vs. normal coronary arteries. This is also supported by the approximately 2.5fold increase in the 3-year incidence of MACE when non-obstructive atheromatosis was present at CCTA. The HR of 151.4 for obstructive CAD vs. normal arteries was considerably higher but also more expected.

All-cause mortality was low $(n=12)$ and the cardiac-related death incidence was even lower $(n=1)$. Cancer was, in fact, a far more common cause of death $(n=8)$, and the possibility that cancer-related pain was erroneously interpreted as being cardiac-related cannot be entirely ignored. However, no further analysis of preCCTA, non-cardiac related morbidity was performed.

We also found a high rate of readmissions even in the groups with normal vessels or non-obstructive CAD. Again, this raises questions about alternative pathology causing the symptoms, but possibly also about patient-doctor communication. Even though earlier trials have indicated a high rate of readmission (112), and correspondingly high health care cost in chest pain patients, this has not been shown in a CCTA population. Thus, a conceivable future study would be to investigate the health care consumption before and after CCTA. 


\section{Limitations}

Apart from the previously discussed limitations of each individual study, it must also be pointed out that all examinations included in this thesis were performed at CMIV/Linköping University Hospital. Although this ensures consistent image acquisition methodology, image quality control and clinical interpretation it also increases the risk of systematic errors in all of these processes. 



\section{FUTURE PERSPECTIVES}

Ever since the introduction of the EMI-scanner in the early 1970s, CT technology has constantly improved at an amazing rate, allowing for ever faster image acquisition, higher resolution, larger field-of view, lower image noise and lower dose. During the last decade, CT has also gone from being a strictly morphological modality to becoming increasingly able to visualise physiological processes, and there is no reason to believe that this trend will not continue. A number of new technologies are on the verge of reaching clinical routine, both in terms of hardware and in terms of advanced software applications.

Among hardware innovations, the photon-counting detector warrants special mentioning. With a potentially unlimited number of spectra, tissue characterisation of coronary plaques and other structures can be expected to be much improved as compared to a conventional detector, thus adding important information in the triage to invasive procedures. In addition, lower noise levels, improved contrast-tonoise ratio, higher spatial resolution and a lower dose can also be expected.

Advanced software applications also continue to be developed, with cFFR presumably being just the beginning. Current research indicate that the application of computational fluid dynamics may also allow for visualisation and quantification of blood flow throughout the cardiac chambers and aorta, thus pushing CT firmly into what has hitherto been strictly MR territory. In addition, cFFR evaluation of coronary stenoses may be supplemented by other techniques such as advanced coronary artery plaque evaluation, measurement of the transluminal attenuation gradient (TAG) and improved versions of CT-based myocardial perfusion imaging.

Apart from technological advances, further knowledge on the value and diagnostic yield of CCTA will also be gained from large, prospective studies such as the Swedish CArdioPulmonary BioImage Study (SCAPIS) trial (113), which will include CCTA and various other imaging methods, physiological tests and laboratory parameters on 30000 randomly chosen persons, aged 50-64. Inclusion is expected to close in 2018.

In conclusion, one single innovative technology may not be sufficient, but the application of several different methods may contribute to a significant increase in diagnostic yield of CT, thereby potentially further reducing the number of unnecessary invasive procedures. Although the use of ionising radiation and iodinated contrast agent still has to be taken into account, CT has the potential to become a true "one-stop-shop" in terms of the cardiac work-up. 
Future perspectives 


\section{CONCLUSIONS}

The studies included in this thesis have led to the following conclusions:

I There was a significant improvement of the perceived image quality and measured image noise of low-dose images with the application of a 2-D, nonlinear adaptive noise reduction filter, even though the improvement was small compared to the image quality of the corresponding diastolic full-dose images.

II There were large variations in CTP blood flow in normal segments on SPECT, rendering the definition of an absolute cut-off value for normal vs. hypoperfused myocardium difficult. Correlation between dynamic CTP and SPECT was positive but weak. Manual and automatic segmentation were equally useful.

III The correlation between cFFR and invFFR was good, indicating that noninvasively estimated cFFR performs on a similar level as invFFR.

IV The long-term risk for MACE was very low in patients with normal coronary arteries or non-obstructive CAD on CCTA, even though there seemed to be a substantial increase in the risk for MACE in patients with non-obstructive CAD as compared to those with normal vessels. In addition, even if patients with non-obstructive coronary artery disease had very low risk of an acute coronary syndrome or revascularisation during extended long-term follow-up, they continued to have a substantial number of readmissions for chest pain or stable angina. 
Conclusions 


\section{POPULÄRVETENSKAPLIG}

\section{SAMMANFATTNING PÅ SVENSKA}

\section{Allmänt}

Datortomografi (DT, CT, CAT-scan, skiktröntgen) är en metod som funnits sedan tidigt 70-tal, och som med hjälp av ett roterande röntgenrör kan avbilda kroppens inre delar. Den resulterande bilden presenteras i första hand som ett tvärsnitt genom den undersökta kroppsdelen, men dagens moderna datortomografer har en så pass god upplösning att bildmaterialet kan vinklas om och presenteras $i$ vilket plan som helst. DT kunde länge endast statiskt avbilda olika strukturer, men under det senaste åren har den tekniska utvecklingen medfört att man även kan använda metoden för att dynamiskt bedöma fysiologiska skeenden, såsom t.ex. genomblödning av hjärtmuskel och hjärna. Den tekniska utvecklingen har också ökat möjligheten att bearbeta ett i grunden statiskt bildmaterial med avseende på fysiologiska frågeställningar.

Undersökning av hjärtats kranskärl med datortomografi (CCTA) har med tiden visat sig vara en enkelt genomförd och användbar undersökning vid misstänkt kranskärlssjukdom. Dock är metoden i många fall förknippad med en relativt hög stråldos, som det är önskvärt att i möjligaste mån sänka. Framförallt är metoden bra på att utesluta kranskärlssjukdom. Mer utbredda kärlförändringar överskattas lätt, och ofta måste patienten då även undersökas med konventionell, invasiv kranskärlsröntgen. I oklara fall kan graden av kärlförträngning då utvärderas genom en tryckmätning framför och bakom förträngningen, och om kvoten mellan dessa understiger 0.8 anses förträngningen vara signifikant. Påvisandet av en signifikant förträngning kan i sin tur leda till åtgärd i form av ballongvidgning (PCI) eller bypassoperation (CABG). Det har dock visat sig att ca $40 \%$ av alla invasiva kranskärlsundersökningar inte visar på några förträngningar, och därmed har utförts i onödan. Då invasiva undersökningar är dyra och det även finns en viss risk för komplikationer är det således önskvärt att öka det diagnostiska utbytet av CCTA, för att på så vis minska antalet onödiga undersökningar.

Denna avhandling fokuserar på ett antal olika aspekter av hjärtundersökning med datortomografi. Delarbete I-III beskriver olika metoder för att förbättra 
bildkvalitet och diagnostiskt utbyte, medan delarbete IV behandlar det prognostiska värdet av CCTA.

\section{Delarbete I}

I detta arbete, med bildmaterial från 36 patienter, undersöktes huruvida bildkvalitet och brusnivåer vid CCTA med låg strålningsdos $(20 \%$ av normalhög dos) kunde förbättras med hjälp av ett brusreduceringsfilter, och i vilken utsträckning bilderna var jämförbara med bilder där normalhög dos utnyttjades. Utvärderingen visade på en viss förbättring av bildkvalitet och brusnivåer vid låg dos, men att förbättringen inte motsvarade bildkvaliteten vid normalhög dos.

\section{Delarbete II}

I denna pilotstudie med 17 deltagande patienter utvärderades en metod (dynamisk DT perfusion, CTP) att med CT dynamiskt avbilda och beräkna hjärtmuskelns genomblödning. Som referensmetod användes en allmänt använd nuklearmedicinsk metod (SPECT), med en annan verkansprincip än CTP. CTP visade sig vara tekniskt komplicerat att utföra, och resultatet visade relativt dålig överensstämmelse mellan de olika metoderna, samtidigt som stråldosen var hög. Med CTP varierade dessutom den beräknade genomsnittliga genomblödningen kraftigt mellan olika delar av hjärtat och mellan olika patienter, även i områden som på SPECT bedömdes som normala. Det var således svårt att med SPECT som referensmetod bestämma ett definitivt gränsvärde för normal genomblödning. Bildmaterialet från CTP-undersökningen hanterades med både en manuell och en automatiserad metod och resultaten jämfördes, utan att någon tydlig skillnad mellan dessa kunde påvisas.

\section{Delarbete III}

I denna studie, med bildmaterial från 21 patienter, utvärderades en programvara som utifrån en vanlig CCTA beräknar tryckfallet över en kärlförträngning, och således dess signifikans. Som referens användes invasiv tryckmätning utförd på samma patient.

Resultaten visade på en relativt god överensstämmelse mellan uppmätt och beräknat tryckfall, och metoden ansågs ha potential att användas i beslutsprocessen kring vidare utredning med invasiv kranskärlsröntgen. 


\section{Delarbete IV}

Detta arbete var en epidemiologisk studie på 1205 patienter utan tidigare känd hjärtsjukdom, som genomgått CCTA pga oklara bröstsmärtor. Beroende på fynden på CCTA delades patienterna in i tre grupper: 1) normala kranskärl, 2) kärlförändringar men ingen signifikant förträngning, 3) signifikant förträngning. Med hjälp av registerdata från det medicinska kvalitetsregistret SWEDEHEART samt Socialstyrelsens patient- och dödsorsaksregister kunde efterföljande hjärtrelaterad sjukdom, död eller invasiv behandling kartläggas. Den längsta uppföljningstiden var 7.5 år och medianuppföljningstiden var 3.1 år.

Resultaten visade på en mycket låg risk för hjärtrelaterad sjukdom eller död i avsaknad av signifikant förträngning. Dock föreföll även icke signifikanta förträngningar ge en 5-faldigt ökad risk för hjärtrelaterad sjukdom eller invasiv åtgärd jämfört med normala kärl. Det visade sig också att många patienter, trots avsaknad av signifikant förträngning på CCTA, i hög utsträckning fortsatte att söka vård pga. bröstsmärtor av oklar orsak. 
Populärvetenskaplig sammanfattning på svenska 


\section{ERRATA}

\begin{tabular}{|c|c|c|c|}
\hline Paper & Page & Original & Corrected \\
\hline II & $2 / 292$ & ... and ref. $\mathrm{mAs}$ at $165 \mathrm{~A}$. & ...and ref. mAs at 300. \\
\hline II & $5 / 295$ & $p<0.0001$ & $p<0.001$ \\
\hline III & 2 & ..., ref. mAs at $185 \mathrm{~A}$. & ..., ref. mAs at 306 or 324. \\
\hline III & 2 & $\begin{array}{l}\text {...in total } 45 \text { patients }(71 \%) \\
\text { representing } 49 \text { vessels (68\%). }\end{array}$ & $\begin{array}{l}\text {...in total } 42 \text { patients }(67 \%) \\
\text { representing } 48 \text { vessels (68\%) }\end{array}$ \\
\hline III & 3 & IBM SPSS, Chicago, IL., USA. & IBM SPSS, Armonk, NY, USA \\
\hline
\end{tabular}


Errata 


\section{ACKNOWLEDGEMENTS}

I wish to express my gratitude to all those who, in different ways, have contributed to the completion of this thesis. In particular, I would like to thank:

Professor Anders Persson and professor Jan Engvall, my main tutors, who with endless enthusiasm and encouragement combined with great patience have coached me towards the final goal. Thank you especially for always being completely available, regardless of all your other commitments!

Professor Örjan Smedby and professor Michael Sandborg, my assistant tutors, for valuable help and support.

Professor Lars Brudin for extensive statistical help, at a time when that help was desperately needed!

Joakim Alfredsson and Mårten Sandstedt, for a very enjoyable team work!

My other co-authors, Marcus Gjerde, Anders Björkholm, Lilian Henriksson, Magnus Janzon and Eva Olsson, for valuable contributions.

Pia Säfström and Mathias Axelsson, former and present head of Department of Radiology at Linköping University Hospital, for encouraging and facilitating research work at the department.

Bengt Petré, Håkan Lindstam, Leif Davidsson, Patrik Fägerstam, Ida Blystad, Inger Eweman, Bea Kovacsovics, Josefin Worda, David Örtoft Alexander Lutfi, Eva Klintström and Anna Borg at the Section of Neuro- and Odontological radiology, for covering for me while I was doing research.

Ingegerd Johansson (in memoriam), former Head of Section of Neuro- and Odontological radiology, who always encouraged my thesis work, in spite of focus being on the wrong organ system. 
Acknowledgements

All other colleagues, co-workers and friends at the Department of Radiology, for friendship and encouragement.

My family-in-law, for kindness and help, whenever needed.

My mother Margaretha and father Göran, for endless enthusiastic support, generosity and love.

My brother Claes with family, for not only being my brother, but also my friend. Thanks especially for the cigars and the late night walks!

And finally, Lina, Ebba and Anna, for being the true lights of my life!

This thesis was supported financially by Region Östergötland and the Swedish Heart-Lung Foundation (Hjärt-Lungfonden), grant no. 20120449.

Thank you also to Siemens Healthcare, for providing prototype CTP and cFFR software, and for those amazing machines! 


\section{REFERENCES}

1. Oldendorf WH. The quest for an image of brain: a brief historical and technical review of brain imaging techniques. Neurology 1978;28:517-33.

2. Littleton JT, Durizch Littleton ML. Conventional Tomography. In: Gagliardi R, McClennan BL, editors. A History of the Radiological Sciences: Diagnosis: Radiology Centennial, 1996:369-401.

3. Hounsfield GN. Computerized transverse axial scanning (tomography). 1. Description of system. Br J Radiol 1973;46:1016-22.

4. Ledley RS, Di Chiro G, Luessenhop AJ, Twigg HL. Computerized transaxial x-ray tomography of the human body. Science (New York, NY) 1974;186:207-12.

5. Moshage WE, Achenbach S, Seese B, Bachmann K, Kirchgeorg M. Coronary artery stenoses: three-dimensional imaging with electrocardiographically triggered, contrast agent-enhanced, electron-beam CT. Radiology 1995;196:707-714.

6. Fischer JJ, Samady H, McPherson JA et al. Comparison between visual assessment and quantitative angiography versus fractional flow reserve for native coronary narrowings of moderate severity. The American journal of cardiology 2002;90:210-5.

7. Fisher LD, Judkins MP, Lesperance J et al. Reproducibility of coronary arteriographic reading in the coronary artery surgery study (CASS). Catheterization and Cardiovascular Diagnosis 1982;8:565-575.

8. Tonino PA, Fearon WF, De Bruyne B et al. Angiographic versus functional severity of coronary artery stenoses in the FAME study fractional flow reserve versus angiography in multivessel evaluation. J Am Coll Cardiol 2010;55:2816-21.

9. Leber AW, Knez A, von Ziegler F et al. Quantification of obstructive and nonobstructive coronary lesions by 64-slice computed tomography: a comparative study with quantitative coronary angiography and intravascular ultrasound. J Am Coll Cardiol 2005;46:147-54.

10. Dehmer GJ, Weaver D, Roe MT et al. A contemporary view of diagnostic cardiac catheterization and percutaneous coronary intervention in the United States: a report from the CathPCI Registry of the National Cardiovascular Data Registry, 2010 through June 2011. J Am Coll Cardiol 2012;60:2017-31.

11. West R, Ellis G, Brooks N, Joint Audit Committee of the British Cardiac S, Royal College of Physicians of L. Complications of diagnostic cardiac catheterisation: results from a confidential inquiry into cardiac catheter complications. Heart 2006;92:810-4.

12. Mettler FA, Jr., Huda W, Yoshizumi TT, Mahesh M. Effective doses in radiology and diagnostic nuclear medicine: a catalog. Radiology 2008;248:254-63.

13. Leschka S, Husmann L, Desbiolles LM et al. Optimal image reconstruction intervals for non-invasive coronary angiography with 64-slice CT. European Radiology 2006;16:19641972. 
14. Husmann L, Leschka S, Desbiolles L et al. Coronary artery motion and cardiac phases: dependency on heart rate -- implications for CT image reconstruction. Radiology 2007;245:567-76.

15. Sabiston DC, Gregg DE. Effect of Cardiac Contraction on Coronary Blood Flow. Circulation 1957;15:14-20.

16. Gerber TC, Carr JJ, Arai AE et al. Ionizing radiation in cardiac imaging: a science advisory from the American Heart Association Committee on Cardiac Imaging of the Council on Clinical Cardiology and Committee on Cardiovascular Imaging and Intervention of the Council on Cardiovascular Radiology and Intervention. Circulation 2009;119:1056-65.

17. Agatston AS, Janowitz WR, Hildner FJ, Zusmer NR, Viamonte M, Detrano R. Quantification of coronary artery calcium using ultrafast computed tomography. Journal of the American College of Cardiology 1990;15:827-832.

18. Budoff MJ, Dowe D, Jollis JG et al. Diagnostic performance of 64-multidetector row coronary computed tomographic angiography for evaluation of coronary artery stenosis in individuals without known coronary artery disease: results from the prospective multicenter ACCURACY (Assessment by Coronary Computed Tomographic Angiography of Individuals Undergoing Invasive Coronary Angiography) trial. J Am Coll Cardiol 2008;52:1724-32.

19. Meijboom WB, van Mieghem CA, Mollet NR et al. 64-slice computed tomography coronary angiography in patients with high, intermediate, or low pretest probability of significant coronary artery disease. J Am Coll Cardiol 2007;50:1469-75.

20. Alkadhi H, Stolzmann P, Desbiolles L et al. Low-dose, 128-slice, dual-source CT coronary angiography: accuracy and radiation dose of the high-pitch and the step-andshoot mode. Heart 2010;96:933-8.

21. Taylor AJ, Cerqueira M, Hodgson JM et al.

ACCF/SCCT/ACR/AHA/ASE/ASNC/NASCI/SCAI/SCMR 2010 Appropriate Use Criteria for Cardiac Computed Tomography. A Report of the American College of Cardiology Foundation Appropriate Use Criteria Task Force, the Society of Cardiovascular Computed Tomography, the American College of Radiology, the American Heart Association, the American Society of Echocardiography, the American Society of Nuclear Cardiology, the North American Society for Cardiovascular Imaging, the Society for Cardiovascular Angiography and Interventions, and the Society for Cardiovascular Magnetic Resonance. J Cardiovasc Comput Tomogr 2010;4:407 e1-33.

22. Raff GL, Chinnaiyan KM, Cury RC et al. SCCT guidelines on the use of coronary computed tomographic angiography for patients presenting with acute chest pain to the emergency department: a report of the Society of Cardiovascular Computed Tomography Guidelines Committee. J Cardiovasc Comput Tomogr 2014;8:254-71.

23. Fihn SD, Gardin JM, Abrams J et al. 2012 ACCF/AHA/ACP/AATS/PCNA/SCAI/STS guideline for the diagnosis and management of patients with stable ischemic heart disease: a report of the American College of Cardiology Foundation/American Heart Association task force on practice guidelines, and the American College of Physicians, American Association for Thoracic Surgery, Preventive Cardiovascular Nurses Association, Society for Cardiovascular 
Angiography and Interventions, and Society of Thoracic Surgeons. Circulation 2012;126:e354-471.

24. Andreini D, Pontone G, Mushtaq S et al. A long-term prognostic value of coronary CT angiography in suspected coronary artery disease. JACC Cardiovasc Imaging 2012;5:690701.

25. Dougoud S, Fuchs TA, Stehli J et al. Prognostic value of coronary CT angiography on long-term follow-up of 6.9 years. Int J Cardiovasc Imaging 2014;30:969-76.

26. Hadamitzky M, Taubert S, Deseive $S$ et al. Prognostic value of coronary computed tomography angiography during 5 years of follow-up in patients with suspected coronary artery disease. Eur Heart J 2013;34:3277-85.

27. Bittencourt MS, Hulten E, Ghoshhajra B et al. Prognostic value of nonobstructive and obstructive coronary artery disease detected by coronary computed tomography angiography to identify cardiovascular events. Circ Cardiovasc Imaging 2014;7:282-91.

28. Yorgun H, Canpolat U, Aytemir K et al. Prognosis of patients with mild-moderate coronary artery stenosis detected by coronary computed tomography angiography. International journal of cardiology 2013;168:1195-200.

29. Achenbach S, Marwan M, Schepis T et al. High-pitch spiral acquisition: a new scan mode for coronary CT angiography. J Cardiovasc Comput Tomogr 2009;3:117-21.

30. Achenbach S, Marwan M, Ropers D et al. Coronary computed tomography angiography with a consistent dose below $1 \mathrm{mSv}$ using prospectively electrocardiogram-triggered highpitch spiral acquisition. Eur Heart J 2010;31:340-6.

31. Yin WH, Lu B, Hou ZH et al. Detection of coronary artery stenosis with sub-milliSievert radiation dose by prospectively ECG-triggered high-pitch spiral CT angiography and iterative reconstruction. Eur Radiol 2013;23:2927-33.

32. Hausleiter J, Meyer T, Hermann $\mathrm{F}$ et al. Estimated radiation dose associated with cardiac CT angiography. Jama 2009;301:500-7.

33. Meijboom WB, Van Mieghem CA, van Pelt $\mathrm{N}$ et al. Comprehensive assessment of coronary artery stenoses: computed tomography coronary angiography versus conventional coronary angiography and correlation with fractional flow reserve in patients with stable angina. J Am Coll Cardiol 2008;52:636-43.

34. Pijls NH, van Son JA, Kirkeeide RL, De Bruyne B, Gould KL. Experimental basis of determining maximum coronary, myocardial, and collateral blood flow by pressure measurements for assessing functional stenosis severity before and after percutaneous transluminal coronary angioplasty. Circulation 1993;87:1354-67.

35. De Bruyne B, Baudhuin T, Melin JA et al. Coronary flow reserve calculated from pressure measurements in humans. Validation with positron emission tomography. Circulation 1994;89:1013-22.

36. Pijls NH, Van Gelder B, Van der Voort P et al. Fractional flow reserve. A useful index to evaluate the influence of an epicardial coronary stenosis on myocardial blood flow.

Circulation 1995;92:3183-93. 


\section{References}

37. Pijls NHJ, de Bruyne B, Peels K et al. Measurement of Fractional Flow Reserve to Assess the Functional Severity of Coronary-Artery Stenoses. New England Journal of Medicine 1996;334:1703-1708.

38. De Bruyne B, Pijls NH, Bartunek J et al. Fractional flow reserve in patients with prior myocardial infarction. Circulation 2001;104:157-62.

39. De Bruyne B, Hersbach F, Pijls NH et al. Abnormal epicardial coronary resistance in patients with diffuse atherosclerosis but "Normal" coronary angiography. Circulation 2001;104:2401-6.

40. De Bruyne B, Sarma J. Fractional flow reserve: a review: invasive imaging. Heart 2008;94:949-59.

41. Taylor CA, Figueroa CA. Patient-specific modeling of cardiovascular mechanics. Annu Rev Biomed Eng 2009;11:109-34.

42. Taylor CA, Fonte TA, Min JK. Computational fluid dynamics applied to cardiac computed tomography for noninvasive quantification of fractional flow reserve: scientific basis. J Am Coll Cardiol 2013;61:2233-41.

43. Zarins CK, Taylor CA, Min JK. Computed fractional flow reserve (FFTCT) derived from coronary CT angiography. J Cardiovasc Transl Res 2013;6:708-14.

44. Kim HJ, Vignon-Clementel IE, Coogan JS, Figueroa CA, Jansen KE, Taylor CA. Patientspecific modeling of blood flow and pressure in human coronary arteries. Ann Biomed Eng 2010;38:3195-209.

45. Hesse B, Tagil K, Cuocolo A et al. EANM/ESC procedural guidelines for myocardial perfusion imaging in nuclear cardiology. Eur J Nucl Med Mol Imaging 2005;32:855-97.

46. Verberne HJ, Acampa W, Anagnostopoulos C et al. EANM procedural guidelines for radionuclide myocardial perfusion imaging with SPECT and SPECT/CT: 2015 revision. Eur J Nucl Med Mol Imaging 2015;42:1929-40.

47. Beller GA, Bergmann SR. Myocardial perfusion imaging agents: SPECT and PET. Journal of Nuclear Cardiology 2004;11:71-86.

48. Salerno M, Beller GA. Noninvasive assessment of myocardial perfusion. Circ Cardiovasc Imaging 2009;2:412-24.

49. Sinusas AJ, Wackers FJ. Assessing myocardial reperfusion with technetium-99m-labeled myocardial perfusion agents: basic concepts and clinical applications. Am J Card Imaging 1993;7:24-38.

50. Schaefer WM, Nowak B, Kaiser HJ et al. Comparison of microsphere-equivalent blood flow (15O-water PET) and relative perfusion (99 $\mathrm{mTc}$-tetrofosmin SPECT) in myocardium showing metabolism-perfusion mismatch. J Nucl Med 2003;44:33-9.

51. Gould KL, Lipscomb K, Hamilton GW. Physiologic basis for assessing critical coronary stenosis. Instantaneous flow response and regional distribution during coronary hyperemia as measures of coronary flow reserve. The American journal of cardiology 1974;33:87-94. 
52. Uren NG, Melin JA, De Bruyne B, Wijns W, Baudhuin T, Camici PG. Relation between myocardial blood flow and the severity of coronary-artery stenosis. New England Journal of Medicine 1994;330:1782-1788.

53. Lima RSL, Watson DD, Goode AR et al. Incremental value of combined perfusion and function over perfusion alone by gated SPECT myocardial perfusion imaging for detection of severe three-vessel coronary artery disease. Journal of the American College of Cardiology 2003;42:64-70.

54. Rossi A, Merkus D, Klotz E, Mollet N, de Feyter PJ, Krestin GP. Stress myocardial perfusion: imaging with multidetector CT. Radiology 2014;270:25-46.

55. Paul JF, Wartski M, Caussin C et al. Late defect on delayed contrast-enhanced multidetector row CT scans in the prediction of SPECT infarct size after reperfused acute myocardial infarction: initial experience. Radiology 2005;236:485-9.

56. Bischoff B, Bamberg F, Marcus R et al. Optimal timing for first-pass stress CT myocardial perfusion imaging. Int J Cardiovasc Imaging 2013;29:435-42.

57. Bamberg F, Klotz E, Flohr T et al. Dynamic myocardial stress perfusion imaging using fast dual-source CT with alternating table positions: initial experience. European Radiology 2010;20:1168-1173.

58. Ho K'T, Chua KC, Klotz E, Panknin C. Stress and rest dynamic myocardial perfusion imaging by evaluation of complete time-attenuation curves with dual-source CT. JACC Cardiovasc Imaging 2010;3:811-20.

59. Kim SM, Choi JH, Chang SA, Choe YH. Detection of ischaemic myocardial lesions with coronary CT angiography and adenosine-stress dynamic perfusion imaging using a 128slice dual-source CT: diagnostic performance in comparison with cardiac MRI. Br J Radiol 2013;86:20130481.

60. Bamberg F, Marcus RP, Becker A et al. Dynamic Myocardial CT Perfusion Imaging for Evaluation of Myocardial Ischemia as Determined by MR Imaging. JACC: Cardiovascular Imaging 2014;7:267-277.

61. Bamberg F, Becker A, Schwarz F et al. Detection of hemodynamically significant coronary artery stenosis: incremental diagnostic value of dynamic CT-based myocardial perfusion imaging. Radiology 2011;260:689-98.

62. Seibert JA. X-Ray Imaging Physics for Nuclear Medicine Technologists. Part 1: Basic Principles of X-Ray Production. Journal of Nuclear Medicine Technology 2004;32:139147.

63. Brenner DJ, Doll R, Goodhead DT et al. Cancer risks attributable to low doses of ionizing radiation: assessing what we really know. Proc Natl Acad Sci U S A 2003;100:13761-6.

64. Ionizing CtAHRfEtLLo, Radiation NRC. Health Risks from Exposure to Low Levels of Ionizing Radiation: BEIR VII Phase 2: The National Academies Press, 2006.

65. Tubiana M, Feinendegen LE, Yang C, Kaminski JM. The linear no-threshold relationship is inconsistent with radiation biologic and experimental data. Radiology 2009;251:13-22. 


\section{References}

66. Siegel JA, Welsh JS. Does Imaging Technology Cause Cancer? Debunking the Linear NoThreshold Model of Radiation Carcinogenesis. Technology in Cancer Research \& Treatment 2016;15:249-256.

67. Coursey CA, Frush DP. CT and radiation: what radiologists should know. Applied radiology 2008;37:22.

68. Huda W, Ogden KM, Khorasani MR. Converting dose-length product to effective dose at CT. Radiology 2008;248:995-1003.

69. Christner JA, Kofler JM, McCollough CH. Estimating Effective Dose for CT Using Dose-Length Product Compared With Using Organ Doses: Consequences of Adopting International Commission on Radiological Protection Publication 103 or Dual-Energy Scanning. American Journal of Roentgenology 2010;194:881-889.

70. European Guidelines on Quality Criteria for Computed Tomography. European Commision 1999;EUR 16262 EN.

71. Geleijns J, Joemai RM, Dewey M et al. Radiation exposure to patients in a multicenter coronary angiography trial (CORE 64). AJR American journal of roentgenology 2011;196:1126-32.

72. Hart D, Jones DG, Wall BF. Estimation of effective dose in diagnostic radiology from entrance surface dose and dose-area product measurements.: National Radiological Protection Board, 1994.

73. Goldman LW. Principles of CT: radiation dose and image quality. J Nucl Med Technol 2007;35:213-25; quiz 226-8.

74. Hounsfield GN. Picture quality of computed tomography. American Journal of Roentgenology 1976;127:3-9.

75. Habibzadeh MA, Ay MR, Asl AR, Ghadiri H, Zaidi H. Impact of miscentering on patient dose and image noise in x-ray CT imaging: phantom and clinical studies. Phys Med 2012;28:191-9.

76. Kataria B, Sandborg M, Althén JN. Implications of patient centring on organ dose in computed tomography. Radiation Protection Dosimetry 2016.

77. Soderberg M, Gunnarsson M. Automatic exposure control in computed tomography--an evaluation of systems from different manufacturers. Acta Radiol 2010;51:625-34.

78. Flohr TG, McCollough CH, Bruder $\mathrm{H}$ et al. First performance evaluation of a dualsource CT (DSCT) system. Eur Radiol 2006;16:256-68.

79. Petersilka M, Bruder H, Krauss B, Stierstorfer K, Flohr TG. Technical principles of dual source CT. Eur J Radiol 2008;68:362-8.

80. Gramer BM, Muenzel D, Leber V et al. Impact of iterative reconstruction on CNR and SNR in dynamic myocardial perfusion imaging in an animal model. European Radiology 2012;22:2654-2661.

81. Ghetti C, Ortenzia O, Serreli G. CT iterative reconstruction in image space: a phantom study. Phys Med 2012;28:161-5. 
82. Leipsic J, Labounty TM, Heilbron B et al. Adaptive statistical iterative reconstruction: assessment of image noise and image quality in coronary CT angiography. AJR American journal of roentgenology 2010;195:649-54.

83. Nelson RC, Feuerlein S, Boll DT. New iterative reconstruction techniques for cardiovascular computed tomography: How do they work, and what are the advantages and disadvantages? Journal of Cardiovascular Computed Tomography 2011;5:286-292.

84. Renker M, Ramachandra A, Schoepf UJ et al. Iterative image reconstruction techniques: Applications for cardiac CT. J Cardiovasc Comput Tomogr 2011;5:225-30.

85. Leipsic J, Labounty TM, Heilbron B et al. Estimated radiation dose reduction using adaptive statistical iterative reconstruction in coronary CT angiography: the ERASIR study. AJR American journal of roentgenology 2010;195:655-60.

86. Månsson LG. Methods for the Evaluation of Image Quality: A Review. Radiation Protection Dosimetry 2000;90:89-99.

87. Båth M, Månsson LG. Visual grading characteristics (VGC) analysis: a non-parametric rank-invariant statistical method for image quality evaluation. The British Journal of Radiology 2007;80:169-176.

88. Jernberg T, Attebring MF, Hambraeus K et al. The Swedish Web-system for enhancement and development of evidence-based care in heart disease evaluated according to recommended therapies (SWEDEHEART). Heart 2010;96:1617-21.

89. Börjesson S, Håkansson M, Båth M et al. A software tool for increased efficiency in observer performance studies in radiology. Radiation Protection Dosimetry 2005;114:4552.

90. Cerqueira MD, Weissman NJ, Dilsizian V et al. Standardized myocardial segmentation and nomenclature for tomographic imaging of the heart. A statement for healthcare professionals from the Cardiac Imaging Committee of the Council on Clinical Cardiology of the American Heart Association. Circulation 2002;105:539-42.

91. Smedby O, Fredrikson M. Visual grading regression: analysing data from visual grading experiments with regression models. Br J Radiol 2010;83:767-75.

92. Patel MR, Peterson ED, Dai D et al. Low diagnostic yield of elective coronary angiography. New England Journal of Medicine 2010;362:886-895.

93. Patel MR, Dai D, Hernandez AF et al. Prevalence and predictors of nonobstructive coronary artery disease identified with coronary angiography in contemporary clinical practice. Am Heart J 2014;167:846-52 e2.

94. Douglas PS, Pontone G, Hlatky MA et al. Clinical outcomes of fractional flow reserve by computed tomographic angiography-guided diagnostic strategies vs. usual care in patients with suspected coronary artery disease: the prospective longitudinal trial of FFR(CT): outcome and resource impacts study. Eur Heart J 2015;36:3359-67.

95. Chow BJW, Small G, Yam Y et al. Incremental Prognostic Value of Cardiac Computed Tomography in Coronary Artery Disease Using CONFIRM: COroNary Computed Tomography Angiography Evaluation for Clinical Outcomes: An InteRnational Multicenter Registry. Circulation: Cardiovascular Imaging 2011;4:463-472. 


\section{References}

96. Mordi I, Tzemos N. The prognostic value of CT coronary angiography in patients attending hospital with troponin-negative acute chest pain and inconclusive exercise treadmill tests. Eur Heart J Cardiovasc Imaging 2015.

97. Sozzi FB, Civaia F, Rossi P et al. Long-term follow-up of patients with first-time chest pain having 64-slice computed tomography. The American journal of cardiology 2011;107:516-21.

98. Johnston DL, Daley JR, Hodge DO, Hopfenspirger MR, Gibbons RJ. Hemodynamic responses and adverse effects associated with adenosine and dipyridamole pharmacologic stress testing: a comparison in 2,000 patients. Mayo Clinic proceedings 1995;70:331-6.

99. Rossen JD, Quillen JE, Lopez AG, Stenberg RG, Talman CL, Winniford MD. Comparison of coronary vasodilation with intravenous dipyridamole and adenosine. J Am Coll Cardiol 1991;18:485-91.

100. Wilson R, Wyche K, Christensen B, Zimmer S, Laxson D. Effects of adenosine on human coronary arterial circulation. Circulation 1990;82:1595-1606.

101. Iskandrian AE, Bateman TM, Belardinelli L et al. Adenosine versus regadenoson comparative evaluation in myocardial perfusion imaging: results of the ADVANCE phase 3 multicenter international trial. J Nucl Cardiol 2007;14:645-58.

102. Al Jaroudi W, Iskandrian AE. Regadenoson: a new myocardial stress agent. J Am Coll Cardiol 2009;54:1123-30.

103. Wang Y, Qin L, Shi X et al. Adenosine-Stress Dynamic Myocardial Perfusion Imaging With Second-Generation Dual-Source CT: Comparison With Conventional Catheter Coronary Angiography and SPECT Nuclear Myocardial Perfusion Imaging. American Journal of Roentgenology 2012;198:521-529.

104. Renker M, Schoepf UJ, Wang R et al. Comparison of Diagnostic Value of a Novel Noninvasive Coronary Computed Tomography Angiography Method Versus Standard Coronary Angiography for Assessing Fractional Flow Reserve. The American journal of cardiology 2014;114:1303-1308.

105. Coenen A, Lubbers MM, Kurata A et al. Fractional flow reserve computed from noninvasive CT angiography data: diagnostic performance of an on-site clinician-operated computational fluid dynamics algorithm. Radiology 2015;274:674-83.

106. Smedby Ö, Fredrikson M, De Geer J, Borgen L, Sandborg M. Quantifying the potential for dose reduction with visual grading regression. The British Journal of Radiology 2013;86:31197714-31197714.

107. Borgen L, Kalra MK, Lærum F et al. Application of adaptive non-linear 2D and 3D postprocessing filters for reduced dose abdominal CT. Acta Radiologica 2012;53:335-342.

108. Nitzsche EU, Choi Y, Czernin J, Hoh CK, Huang S-C, Schelbert HR. Noninvasive Quantification of Myocardial Blood Flow in Humans: A Direct Comparison of the [13N]Ammonia and the [15O]Water Techniques. Circulation 1996;93:2000-2006.

109. Rossi A, Uitterdijk A, Dijkshoorn M et al. Quantification of myocardial blood flow by adenosine-stress CT perfusion imaging in pigs during various degrees of stenosis correlates well with coronary artery blood flow and fractional flow reserve. European Heart Journal - Cardiovascular Imaging 2013;14:331-338. 
110. Min JK, Leipsic J, Pencina MJ, et al. DIagnostic accuracy of fractional flow reserve from anatomic ct angiography. Jama 2012;308:1237-1245.

111. Nørgaard BL, Leipsic J, Gaur S et al. Diagnostic Performance of Noninvasive Fractional Flow Reserve Derived From Coronary Computed Tomography Angiography in Suspected Coronary Artery Disease: The NXT Trial (Analysis of Coronary Blood Flow Using CT Angiography: Next Steps). Journal of the American College of Cardiology 2014;63:1145-1155.

112. Herlitz J, Karlson BW, Sjolin M. Re-admissions among patients with acute chest pain who were discharged from the emergency department. European journal of emergency medicine : official journal of the European Society for Emergency Medicine 1996;3:31-5.

113. Bergstrom G, Berglund G, Blomberg A et al. The Swedish CArdioPulmonary BioImage Study: objectives and design. J Intern Med 2015;278:645-59. 
References 
APPENDIX (PAPERS I - IV) 



\section{Papers}

The articles associated with this thesis have been removed for copyright reasons. For more details about these see:

http://urn.kb.se/resolve?urn=urn:nbn:se:liu:diva-128276 